\title{
Genetic diversity and population structure of Musa accessions in ex situ conservation
}

Onildo Nunes de Jesus ${ }^{1,2,3^{*}}$, Sebastião de Oliveira e Silva ${ }^{3}$, Edson Perito Amorim ${ }^{3}$, Claudia Fortes Ferreira ${ }^{3}$, José Marcello Salabert de Campos ${ }^{4}$, Gabriela de Gaspari Silva ${ }^{1}$ and Antonio Figueira ${ }^{1 *}$

\begin{abstract}
Background: Banana cultivars are mostly derived from hybridization between wild diploid subspecies of Musa acuminata (A genome) and M. balbisiana (B genome), and they exhibit various levels of ploidy and genomic constitution. The Embrapa ex situ Musa collection contains over 220 accessions, of which only a few have been genetically characterized. Knowledge regarding the genetic relationships and diversity between modern cultivars and wild relatives would assist in conservation and breeding strategies. Our objectives were to determine the genomic constitution based on Internal Transcribed Spacer (ITS) regions polymorphism and the ploidy of all accessions by flow cytometry and to investigate the population structure of the collection using Simple Sequence Repeat (SSR) loci as co-dominant markers based on Structure software, not previously performed in Musa.

Results: From the 221 accessions analyzed by flow cytometry, the correct ploidy was confirmed or established for 212 (95.9\%), whereas digestion of the ITS region confirmed the genomic constitution of 209 (94.6\%). Neighborjoining clustering analysis derived from SSR binary data allowed the detection of two major groups, essentially distinguished by the presence or absence of the B genome, while subgroups were formed according to the genomic composition and commercial classification. The co-dominant nature of SSR was explored to analyze the structure of the population based on a Bayesian approach, detecting 21 subpopulations. Most of the subpopulations were in agreement with the clustering analysis.

Conclusions: The data generated by flow cytometry, ITS and SSR supported the hypothesis about the occurrence of homeologue recombination between A and B genomes, leading to discrepancies in the number of sets or portions from each parental genome. These phenomenons have been largely disregarded in the evolution of banana, as the "single-step domestication" hypothesis had long predominated. These findings will have an impact in future breeding approaches. Structure analysis enabled the efficient detection of ancestry of recently developed tetraploid hybrids by breeding programs, and for some triploids. However, for the main commercial subgroups, Structure appeared to be less efficient to detect the ancestry in diploid groups, possibly due to sampling restrictions. The possibility of inferring the membership among accessions to correct the effects of genetic structure opens possibilities for its use in marker-assisted selection by association mapping.
\end{abstract}

Keywords: Association mapping, Banana, Evolution, Flow cytometry, Internal transcribed spacer, Microsatellite, Simple sequence repeat, Structure

\footnotetext{
*Correspondence: onildo.nunes@embrapa.br; figueira@cena.usp.br

${ }^{1}$ Centro de Energia Nuclear na Agricultura, Universidade de São Paulo, Av.

Centenário, 303, CP 96, Piracicaba, SP 13400-970, Brazil

Escola Superior de Agricultura "Luiz de Queiroz", Universidade de São Paulo,

Av. Pádua Dias, 11, Piracicaba, SP 13418-900, Brazil

Full list of author information is available at the end of the article
} 


\section{Background}

Cultivated bananas and plantains (Musa spp.) originated in Southeast Asia and the Western Pacific [1,2]. From the center of origin, Musa spp. was introduced into Africa in ancient times and taken by European explorers to the Americas and other parts of the world $[3,4]$. Currently, bananas and plantains (hereafter jointly called bananas) are widely cultivated in tropical and subtropical regions as important staple foods and commodities in many countries [5].

The large majority of banana cultivars are derived from natural crosses between wild seeded diploid subspecies of $M$. acuminata Colla (A genome) and $M$. balbisiana Colla (B genome) [6]. Most of modern cultivars contains genome combinations with various levels of ploidy, such as diploid (AA; BB; or AB; $2 n=2 x=22$ ); triploid (AAA; $\mathrm{AAB}$; or $\mathrm{ABB} ; 2 n=3 x=33$ ); and tetraploid (AAAA; AAAB; AABB; or ABBB; $2 n=4 x=44$ ) [6]. It is not well established how wild bananas became domesticated, but it is possible that the accumulation of sterility and acquisition of parthenocarpy with the increase of pulp mass and the absence of seeds, followed by human selection, gave rise to the modern predominantly sterile cultivars [7-10].

There are a limited number of ex situ conservation collections in the world (http://www.crop-diversity.org/ banana/) and even fewer breeding programs associated with an important collection. One of these rare examples is the germplasm collection maintained at 'Embrapa Mandioca Fruticultura' Center, located at Cruz das Almas, Bahia, Brazil (12³9'59"S; 3906'00"W). This ex situ collection, with over 220 individual accessions, is derived from the efforts begun in 1981 by the late Dr. Kenneth Shepherd, who used his significant personal networking and credibility with international organizations to obtain and introduce Musa spp. germplasm from various countries [11]. Despite the fact that a wide range of genetic resources is maintained, only a few accessions have been used in the breeding program, possibly because of the lack of characterization and genetic identity.

The precise determination of the ploidy and genomic composition of the accessions are of great interest to define hybridization programs, as the combination of these two genomes ( $\mathrm{A}$ and $\mathrm{B}$ ) defines the agronomical attributes (for e.g., yield; resistance to biotic factors) as well as the fruit flavor and quality of the resulting hybrid plants [12-14]. In addition, estimation of genetic diversity and genetic relationships among the various wild and cultivated accessions will help to develop novel approaches for breeding and assist long-term conservation strategies.

To determine ploidy in Musa spp., chromosome counting [15], estimation of the stomata size and density, or measurement of the pollen grain sizes have been employed [16], whereas for the characterization of the genomic composition (genome $\mathrm{A}$ and/or B), a set of 15 standard morphological descriptors have been traditionally used [6]. However, these conventional methods are imprecise, suffering from large environmental effects, and they are tedious and time-consuming, and not applicable on a large scale. Flow cytometry is a quick method that is able to detect small variations in DNA content and efficient for determining ploidy level in Musa spp. [17-19]. To determine the genomic composition of the Musa genus, PCRRFLP markers based on the rDNA region developed by Nwakanma et al. [20] appeared to be effective [21], but the results are limited in terms of the ability to estimate the genetic diversity. On the other hand, simple sequence repeat (SSR) loci with genome-specific alleles [22,23] offer the possibility to identify genomic composition and to estimate the genetic diversity and relationships among accessions from an ex situ conservation collection.

Despite the multiallelic and highly informative nature of microsatellite (SSR) loci, the allelic information in Musa had usually been converted into binary data due to the difficulty in establishing allelic relations between heterozygous genotypes with distinct levels of ploidy [9,21,22,24-29] and polysomic inheritance [29]. The exploration of the co-dominant nature of SSR loci using Bayesian models implemented using the software Structure [30-32] might enable new perspectives of establishing allelic relationships between various accessions to infer about ancestry between cultivars and wild accessions and $M$. acuminata subspecies. The determination of the genetic structure in ex situ collections is important to determine the genetic relationships [11,33] and to establish core collections [34]. Further, the use of Structure would enable the estimation of a membership matrix among the accessions, adopted in association mapping models [35] to correct the genetic structuring that leads to false associations (false positives). Association mapping is an approach particularly well suited for Musa spp., because non-related individuals can be sampled in a population, such as an $e x$ situ germplasm collection or collections of elite varieties [36-38], without the requirement to develop segregating populations, limited in Musa by sterility, incompatibility [39], low viability of the hybrids due to chromosomal aberrations, and segregation of unviable gene alleles $[40,41]$.

Therefore, the objectives of this study were (i) to characterize the accessions of the ex situ conservation collection in Brazil regarding ploidy and the genomic constitution by flow cytometry and PCR-RFLP; and (ii) to establish the genetic relationships by exploring the co-dominant nature of the SSR loci using the Bayesian model implemented on Structure. 


\section{Methods}

Plant material

A total of 224 accessions of the Musa genus were analyzed, including wild and cultivated materials with apparent diverse ploidy and genomic constitution (Table 1; Additional file 1: Table S1). The only passport information available was the origin of the accessions, with a presumed genomic constitution. Classification of the banana accessions as members of subgroups (such as 'Pome'; 'Silk'; and 'Cavendish') had previously been performed by breeders. Other information, such the subspecies or subgroup, was obtained from the Musa Germplasm Information System (http://www.cropdiversity.org/banana/) [42].

\section{Flow cytometry analyses}

To determine the ploidy, approximately 20 to $30 \mathrm{mg}$ of fresh young healthy leaf tissue from each sample, in addition to the same amount of internal standard Pisum sativum [43], were finely chopped with a blade in a Petri dish containing appropriate buffer [44] to lyse the cells and release the nuclei into the suspension. The nuclei suspension was then filtered through a $50 \mu \mathrm{m}$ screen and stained with $25 \mu \mathrm{L}$ of $1 \mathrm{mg} \mathrm{mL}^{-1}$ propidium iodide, followed by the addition of $5 \mu \mathrm{L}$ of RNase solution $\left(100 \mu \mathrm{g} \mathrm{mL} \mathrm{m}^{-1}\right)$. Each accession was represented by samples from three individual with one leaf each. For each sample, at least 10,000 nuclei were analyzed using a FACSCalibur flow cytometer (Becton Dickinson \& Co.; San Jose, CA, USA), and histograms with the nuclei counts and fluorescence values were obtained using the software CellQuest (Becton Dickinson). Statistics for DNA content were estimated using WinMDI 2.8 (http:// facs.scripps.edu/software.html). The DNA content was expressed in pg (2C), estimated based on the P. sativum standard as $2 \mathrm{C}=9.09 \mathrm{pg}$.

\section{Amplification of the internal transcribed spacers (ITS) for PCR-RFLP}

The ITS1-5.8S-ITS2 regions of the nuclear ribosomal gene were amplified using the primers ITS1 and ITS4 [45] for the PCR-RFLP method [20]. The amplification reaction (with a final volume of $25 \mu \mathrm{L}$ and $25 \mathrm{ng}$ genomic DNA) and cycling conditions were identical as proposed by [20], except for primer concentration $(0.2 \mu \mathrm{M}$ of each primer). Five $\mu \mathrm{L}$ of each reaction were used to confirm the amplification by gel electrophoresis. The remaining $20 \mu \mathrm{L}$ were then digested with $2 \mathrm{U} R s a \mathrm{I}$ (Fermentas), after adding $2.5 \mu \mathrm{L} 1 \mathrm{X}$ Tango buffer, for $3 \mathrm{~h}$ at $37^{\circ} \mathrm{C}$ and visualized by $2 \%$ agarose gel electrophoresis in $0.5 \mathrm{X}$ TBE (90 mM Tris; $90 \mathrm{mM}$ boric acid; $2.5 \mathrm{mM}$ EDTA, pH 8.3) ran for $2 \mathrm{~h}$ at $4 \mathrm{~V} \mathrm{~cm}^{-1}$.

To discriminate mixtures of genomes at various dosages, the profiles of fragments and band intensities were initially established by sequential mixtures of DNA samples from the $M$. acuminata (AA; 'Calcutta 4') and the $M$. balbisiana (BB; 'Butuhan') genomes to obtain various artificial combinations of genomes. In a first assay, equimolar amounts of DNA from $\mathrm{AA}$ and $\mathrm{BB}$ were combined in the following molar proportions: $1 \mathrm{AA}: 2 \mathrm{BB}$; $1 \mathrm{AA}: 1 \mathrm{BB} ; 2 \mathrm{AA}: 1 \mathrm{BB}$; and $3 \mathrm{AA}: 1 \mathrm{BB}$ to simulate $\mathrm{ABB}, \mathrm{AB}, \mathrm{AAB}$, and $\mathrm{AAAB}$, respectively. For the second assay, the ratios $2 \mathrm{AA}: 1 \mathrm{BB} ; 1 \mathrm{AA}: 1 \mathrm{BB} ; 1 \mathrm{AA}: 2 \mathrm{BB}$; and $1 \mathrm{AA}: 3 \mathrm{BB}$ were prepared to simulate $\mathrm{AAB}, \mathrm{AB}, \mathrm{ABB}$ and ABBB genotypes, respectively. Accessions 20 (ABB); 53 $(\mathrm{AAB}) ; 84(\mathrm{AAAB})$; and $142(\mathrm{AA})$ with known genomic constitutions (Additional file 1: Table S1) were used as positive controls for both assays (Figure 1).

\section{Analyses of SSR loci}

A total of 21 SSR loci were tested (Additional file 1: Table S2), including two loci from the 'Ma' series [46]; three from the 'AGMI' series [47]; four 'Mb' locus derived from $M$. balbisiana [48]; eight derived from the M. acuminata commercial cultivar 'Ouro'(AA) (MaO) [23]; and four new loci, being two from 'Ouro' (MaO$C E N$ ) and another two from $M$. acuminata 'Calcutta 4' $(M a C-C E N)$. The amplification reactions contained $25 \mathrm{ng}$ of DNA; $1.5 \mathrm{mM} \mathrm{MgCl}_{2} ; 100 \mu \mathrm{M}$ of each dNTPs; $0.2 \mu \mathrm{M}$ of each primer and 1.2 U Taq polymerase in $1 \mathrm{x}$ PCR buffer (Fermentas) in a final volume of $10 \mu \mathrm{L}$. The amplifications were conducted using a touchdown cycle [23]. The loci were analyzed in an automatic DNA analyzer, and the amplification reactions were conducted for each locus separately, each with a forward primer containing one of the three additional tail sequences [49] equivalent to a fluorescent primer that was at a concentration of $0.02 \mu \mathrm{M}$. An aliquot of $1 \mu \mathrm{L}$ of each amplification reaction for each one of the three fluorescence of each individual was mixed with $12 \mu \mathrm{L}$ of $\mathrm{Hi}$-Di formamide (Applied Biosystems) and $0.5 \mu \mathrm{L}$ of the ROX-500 size standard (35-500 bp) (Applied Biosystems) at an original concentration of $8 \mathrm{nM}$. This mixture was then denatured at $94^{\circ} \mathrm{C}$ for $5 \mathrm{~min}$ and kept on ice before injection. The samples were loaded into an ABI PRISM 310 Genetic Analyzer, and the results were analyzed using a GeneScan and Genotyper (Applied Biosystems).

\section{Statistical analysis of the SSR data}

For all accessions $(2 x ; 3 x$; and $4 x)$, the polymorphic information content (PIC) was estimated for each SSR locus as $P I C_{i}=2 f_{i}\left(1-f_{i}\right)$, where $i$ is the information of the $i^{t h}$ marker; $f_{i}$ is the frequency of the amplified allele (presence of a band) and $\left(1-f_{i}\right)$ is the frequency of null alleles [50]. PIC was presented as the mean over the various loci. The Marker Index (MI) was estimated as $M I=P I C \times E M R$, where $E M R$ is the effective multiplex relation given by the product between the total number 
Table 1 Musa accessions from the ex situ collection of 'Embrapa Mandioca Fruticultura' Center (Cruz das Almas, Brazil) with information from passport data, and characterization of genomic constitution by flow cytometry, PCR-RFLP of internal transcribed spacers (ITS) regions, and Simple Sequence Region (SSR) loci

\begin{tabular}{|c|c|c|c|c|c|c|c|c|c|}
\hline \multirow[t]{3}{*}{ No } & \multirow[t]{3}{*}{ Acession } & \multirow[b]{3}{*}{ Genome $^{z}$} & \multirow{2}{*}{\multicolumn{2}{|c|}{ Cytometry }} & \multicolumn{5}{|c|}{ Molecular markers } \\
\hline & & & & & \multicolumn{5}{|c|}{ ITS fragments (bp) } \\
\hline & & & $2 \mathrm{Cpg}$ & Ploidy & 530 & 350 & 180 & Genome & SSR $^{v}$ \\
\hline 1 & Musa basjoo & ES & 1.23 & $2 x$ & ++ & ++ & & - & - \\
\hline 2 & Piraí & BB & 1.22 & $2 x$ & & ++ & ++ & BB & BB \\
\hline 3 & Butuhan & BB & 1.23 & $2 x$ & & ++ & ++ & BB & $\mathrm{BB}$ \\
\hline 4 & BB Panama & BB & 1.30 & $2 x$ & & ++ & ++ & BB & BB \\
\hline 5 & Balbisiana França & BB & 1.27 & $2 x$ & & ++ & ++ & BB & BB \\
\hline 6 & Musa Balbisiana & BB & 1.25 & $2 x$ & & ++ & ++ & BB & $\mathrm{BB}$ \\
\hline 7 & $\mathrm{TIP}$ & $A B B$ & 1.98 & $3 x$ & ++ & + & + & $A A B$ & $A A B$ \\
\hline 8 & Saba Honduras & $A B B$ & 1.93 & $3 x$ & ++ & ++ & ++ & $A B B$ & $A B B$ \\
\hline 9 & Saba & $A B B$ & 1.95 & $3 x$ & ++ & ++ & ++ & $\mathrm{ABB}$ & $A B B$ \\
\hline 10 & Prata Zulu & $A B B$ & $M^{x}$ & $?^{W}$ & ++ & + & + & $\mathrm{ABB} / \mathrm{AAB}$ & $A B B$ \\
\hline 11 & Poteau Nain & $A B B$ & M & $?$ & ++ & + & + & $A B B / A A B$ & $A B B$ \\
\hline 12 & Pelipita & $A B B$ & 1.89 & $3 x$ & ++ & ++ & ++ & $A B B$ & $A B B$ \\
\hline 13 & Namwa Khom & $A B B$ & 1.91 & $3 x$ & ++ & ++ & ++ & $A B B$ & $A B B$ \\
\hline 14 & Namwa Daeng & $A B B$ & 1.94 & $3 x$ & ++ & ++ & ++ & $A B B$ & $A B B$ \\
\hline 15 & Muisa Tia & $A B B$ & 1.90 & $3 x$ & ++ & ++ & ++ & $A B B$ & $A B B$ \\
\hline 16 & Monthan & $A B B$ & 1.93 & $3 x$ & ++ & ++ & ++ & $A B B$ & $A B B$ \\
\hline 17 & Ice Cream & ABB & 1.94 & $3 x$ & ++ & ++ & ++ & $A B B$ & $A B B$ \\
\hline 18 & Ice Cream & $A B B$ & 1.93 & $3 x$ & ++ & ++ & ++ & $A B B$ & $A B B$ \\
\hline 19 & Gia Hui & $A B B$ & 1.90 & $3 x$ & ++ & ++ & ++ & $A B B$ & $A B B$ \\
\hline 20 & Figo Cinza & $A B B$ & 1.86 & $3 x$ & ++ & ++ & ++ & $A B B$ & $A B B$ \\
\hline 21 & Espermo & $A B B$ & M & $?$ & ++ & ++ & ++ & $A B B$ & $A B B$ \\
\hline 22 & Champa Madras & $A B B$ & 1.98 & $3 x$ & ++ & ++ & ++ & $A B B$ & $A B B$ \\
\hline 23 & Cachaco & $A B B$ & 1.93 & $3 x$ & ++ & ++ & ++ & $A B B$ & $A B B$ \\
\hline 24 & Cacambou Naine & $A B B$ & 1.93 & $3 x$ & ++ & ++ & ++ & $A B B$ & $A B B$ \\
\hline 25 & Bendetta & $A B B$ & 1.93 & $3 x$ & ++ & ++ & ++ & $A B B$ & $A B B$ \\
\hline 26 & Abuperak & $A B B$ & 1.94 & $3 x$ & ++ & ++ & ++ & $A B B$ & $A B B$ \\
\hline 27 & IAC & $\mathrm{AB}(\mathrm{H})$ & 1.26 & $2 x$ & ++ & + & + & $A B$ & $?$ \\
\hline 28 & Yangambi no 2 & $A A B$ & 1.93 & $3 x$ & ++ & & & AAA & $A A B$ \\
\hline 29 & Warik & $A A B$ & 1.94 & $3 x$ & ++ & + & + & $A A B$ & $A A B$ \\
\hline 30 & Walha & $A A B$ & 1.95 & $3 x$ & ++ & + & + & $A A B$ & $A A B$ \\
\hline 31 & Ustrali & $A A B$ & 1.93 & $3 x$ & ++ & + & + & $A A B$ & $A A B$ \\
\hline 32 & Umpako & $A A B$ & 1.89 & $3 x$ & ++ & + & + & $A A B$ & $A A B$ \\
\hline 33 & Thap Maeo & $A A B$ & 1.94 & $3 x$ & ++ & + & + & $A A B$ & $A A B$ \\
\hline 34 & Trois Vert & $A A B$ & 1.90 & $3 x$ & ++ & + & + & $A A B$ & $A A B$ \\
\hline 35 & Tomnam & $A A B$ & 1.94 & $3 x$ & ++ & + & + & $A A B$ & $A A B$ \\
\hline 36 & Tipo Velhaca & $A A B$ & 1.92 & $3 x$ & ++ & + & + & $A A B$ & $A A B$ \\
\hline 37 & Tip Kham & $A A B$ & 1.87 & $3 x$ & ++ & + & + & $A A B$ & $A A B$ \\
\hline 38 & Thong Ruong & $A A B$ & 1.98 & $3 x$ & ++ & + & + & $A A B$ & $A A B$ \\
\hline 39 & Terrinha & $A A B$ & 1.94 & $3 x$ & ++ & + & + & $A A B$ & $A A B$ \\
\hline 40 & Terra S/ Nome & $A A B$ & 1.94 & $3 x$ & ++ & + & + & $A A B$ & $A A B$ \\
\hline
\end{tabular}


Table 1 Musa accessions from the ex situ collection of 'Embrapa Mandioca Fruticultura' Center (Cruz das Almas, Brazil) with information from passport data, and characterization of genomic constitution by flow cytometry, PCR-RFLP of internal transcribed spacers (ITS) regions, and Simple Sequence Region (SSR) loci (Continued)

\begin{tabular}{|c|c|c|c|c|c|c|c|c|c|}
\hline 41 & Tai & $A B B$ & 1.99 & $3 x$ & ++ & ++ & ++ & $\mathrm{ABB}$ & $\mathrm{ABB}$ \\
\hline 42 & Sempre Verde & $A A B$ & 1.94 & $3 x$ & ++ & + & + & $A A B$ & $A A B$ \\
\hline 43 & Saney & $A A B$ & 1.94 & $3 x$ & ++ & + & + & $A A B$ & $A A B$ \\
\hline 44 & Samurá B & $A A B$ & 1.89 & $3 x$ & ++ & + & + & $A A B$ & $A A B$ \\
\hline 45 & Red Yade & $A A B$ & 1.95 & $3 x$ & ++ & + & + & $A A B$ & $A A B$ \\
\hline 46 & Pulut & $A A B$ & 1.94 & $3 x$ & ++ & + & + & $A A B$ & $A A B$ \\
\hline 47 & Pratão & $A A B$ & 1.95 & $3 x$ & ++ & + & + & $A A B$ & $A A B$ \\
\hline 48 & Prata Sta. Maria & $A A B$ & 1.94 & $3 x$ & ++ & + & + & $A A B$ & $A A B$ \\
\hline 49 & Prata P. Aparada & $A A B$ & 1.95 & $3 x$ & ++ & + & + & $A A B$ & $A A B$ \\
\hline 50 & Prata Maceió & $A A B$ & 1.93 & $3 x$ & ++ & + & + & $A A B$ & $A A B$ \\
\hline 51 & Prata Comum & $A A B$ & 1.90 & $3 x$ & ++ & + & + & $A A B$ & $A A B$ \\
\hline 52 & Prata IAC & $A A B$ & 1.99 & $3 x$ & ++ & + & + & $A A B$ & $A A B$ \\
\hline 53 & Prata Anã & $A A B$ & 1.94 & $3 x$ & ++ & + & + & $A A B$ & $A A B$ \\
\hline 54 & Prata Branca & $A A B$ & 2.29 & $4 x$ & ++ & + & + & AAAB & $A A B$ \\
\hline 55 & Poovan & $A A B$ & 1.94 & $3 x$ & ++ & + & + & $A A B$ & $A A B$ \\
\hline 56 & Plantain N. 2 & $A A B$ & $?$ & $?$ & ++ & + & + & $A B ?$ & $A A B$ \\
\hline 57 & Pinha & $A A B$ & 1.94 & $3 x$ & ++ & + & + & $A A B$ & $A A B$ \\
\hline 58 & Padath & $A A B$ & 1.95 & $3 x$ & ++ & + & + & $A A B$ & $A A B$ \\
\hline 59 & Pacovan & $A A B$ & 1.93 & $3 x$ & ++ & + & + & $A A B$ & $A A B$ \\
\hline 60 & N. 113 & $A A B$ & 1.89 & $3 x$ & ++ & + & + & $A A B$ & $A A B$ \\
\hline 61 & Mysore & $A A B$ & 1.95 & $3 x$ & ++ & + & + & $A A B$ & $A A B$ \\
\hline 62 & Muracho & $A A B$ & 1.95 & $3 x$ & ++ & + & + & $A A B$ & $A A B$ \\
\hline 63 & Mongolo & $A A B$ & 1.98 & $3 x$ & ++ & + & + & $A A B$ & $A A B$ \\
\hline 64 & Moenang & $A A B$ & 1.99 & $3 x$ & ++ & + & + & $A A B$ & $A A B$ \\
\hline 65 & Maçã Caule Roxo & $A A B$ & 1.90 & $3 x$ & ++ & + & + & $A A B$ & $A A B$ \\
\hline 66 & Kune & $A A B$ & 1.92 & $3 x$ & ++ & + & + & $A A B$ & $A A B$ \\
\hline 67 & Kingala N.1 & $A A B$ & 1.95 & $3 x$ & ++ & + & + & $A A B$ & $A A B$ \\
\hline 68 & Kepok Bung & $A A B$ & 1.95 & $3 x$ & ++ & + & + & $\mathrm{ABB} / \mathrm{AAB}$ & $\mathrm{ABB} / \mathrm{AAB}$ \\
\hline 69 & Kelat & $A A B$ & 1.87 & $3 x$ & ++ & + & + & $A A B$ & $A A B$ \\
\hline 70 & Java IAC & $A A B$ & 1.99 & $3 x$ & ++ & + & + & $A A B$ & $A A B$ \\
\hline 71 & Garoto & $A A B$ & 1.93 & $3 x$ & ++ & + & + & $A A B$ & $A A B$ \\
\hline 72 & Figue Rose Naine & $A A B$ & 1.93 & $3 x$ & ++ & & & AAA & AAA \\
\hline 73 & Eslesno & $A A B$ & 1.95 & $3 x$ & ++ & + & + & $A A B$ & $A A B$ \\
\hline 74 & Curare Enano & $A A B$ & 1.99 & $3 x$ & ++ & + & + & $A A B$ & $A A B$ \\
\hline 75 & Comprida & $A A B$ & 1.98 & $3 x$ & ++ & + & + & $A A B$ & $A A B$ \\
\hline 76 & Chifre De Vaca & $A A B$ & 1.92 & $3 x$ & ++ & + & + & $A A B$ & $A A B$ \\
\hline 77 & Adimoo & $A A B$ & 1.93 & $3 x$ & ++ & + & + & $A A B$ & $A A B$ \\
\hline 78 & AAB S/Nome & $A A B$ & 1.95 & $3 x$ & ++ & + & + & $A A B$ & $A A B$ \\
\hline 79 & BRS Tropical & AAAB & 2.50 & $4 x$ & ++ & & & AAAA & AAAB \\
\hline 80 & Preciosa & $A A A B$ & 1.94 & $3 x$ & ++ & + & + & $A A B$ & $A A A B$ \\
\hline 81 & Porp & AAAB & 2.43 & $4 x$ & ++ & & & $A A A B$ & AAAB \\
\hline 82 & Platina & $A A A B$ & 2.56 & $4 x$ & ++ & + & + & $A A A B$ & $A A A B$ \\
\hline
\end{tabular}


Table 1 Musa accessions from the ex situ collection of 'Embrapa Mandioca Fruticultura' Center (Cruz das Almas, Brazil) with information from passport data, and characterization of genomic constitution by flow cytometry, PCR-RFLP of internal transcribed spacers (ITS) regions, and Simple Sequence Region (SSR) loci (Continued)

\begin{tabular}{|c|c|c|c|c|c|c|c|c|c|}
\hline 83 & Pacova Ken & $A A A B$ & 2.45 & $4 x$ & ++ & + & + & $A A A B$ & $\mathrm{AAAB}$ \\
\hline 84 & BRS Platina & $A A A B$ & 2.45 & $4 x$ & ++ & + & + & $A A A B$ & AAAB \\
\hline 85 & Ouro Da Mata & $A A A B$ & 2.46 & $4 x$ & ++ & + & + & $A A A B$ & AAAB \\
\hline 86 & Ngern & $A A A B$ & 2.55 & $4 x$ & ++ & + & + & $A A A B$ & $\mathrm{AAAB}$ \\
\hline 87 & Langka & $A A A B$ & 2.48 & $4 \mathrm{x}$ & ++ & + & + & $A A A B$ & AAAB \\
\hline 88 & Garantida & AAAB & 2.48 & $4 x$ & ++ & + & + & $A A A B$ & AAAB \\
\hline 89 & FHIA-21 & $A A A B$ & 2.49 & $4 x$ & ++ & + & + & $A A A B$ & $\mathrm{AAAB}$ \\
\hline 90 & FHIA-18 & $A A A B$ & 2.48 & $4 x$ & ++ & + & + & $A A A B$ & AAAB \\
\hline 91 & FHIA-02 & AAAB/AAAA & 2.40 & $4 x$ & ++ & + & + & $A A A B$ & $\mathrm{AAAB}$ \\
\hline 92 & FHIA-01 & $A A A B$ & 2.49 & $4 x$ & ++ & + & + & $A A A B$ & $\mathrm{AAAB}$ \\
\hline 93 & IC -2 & AAAA & 2.49 & $4 \mathrm{x}$ & ++ & & & AAAA & AAAA \\
\hline 94 & Calypso & AAAA & 2.43 & $4 x$ & ++ & & & AAAA & AAAA \\
\hline 95 & Buccaneer & AAAA & 2.45 & $4 x$ & ++ & & & AAAA & AAAA \\
\hline 96 & Ambrosia & AAAA & 2.47 & $4 x$ & ++ & & & AAAA & AAAA \\
\hline 97 & Yangambi Km 5 & AAA & 1.92 & $3 x$ & ++ & & & AAA & AAA \\
\hline 98 & Wasolay & AAA & 1.92 & $3 x$ & ++ & & & AAA & AAA \\
\hline 99 & Walebo & AAA & 1.98 & $3 x$ & ++ & & & AAA & AAA \\
\hline 100 & Valery & AAA & 1.98 & $3 x$ & ++ & & & AAA & AAA \\
\hline 101 & Umbuk & AAA & 1.95 & $3 x$ & ++ & & & AAA & AAA \\
\hline 102 & Tugoomomboo & AAA & $?$ & $?$ & ++ & ++ & ++ & $\mathrm{ABB}$ & $A A B$ \\
\hline 103 & Caipira & AAA & 1.98 & $3 x$ & ++ & & & AAA & AAA \\
\hline 104 & Towoolee & AAA & 1.90 & $3 x$ & ++ & & & AAA & AAA \\
\hline 105 & Torp & AAA & 1.90 & $3 x$ & ++ & & & AAA & AAA \\
\hline 106 & Sri & AAA & 1.93 & $3 x$ & ++ & & & AAA & AAA \\
\hline 107 & Sapon & AAA & 1.93 & $3 x$ & ++ & & & AAA & AAA \\
\hline 108 & São Tomé & AAA & 1.92 & $3 x$ & ++ & & & AAA & AAA \\
\hline 109 & Roombum & AAA & 1.92 & $3 x$ & ++ & & & AAA & AAA \\
\hline 110 & Poyo & AAA & 1.91 & $3 x$ & ++ & & & AAA & AAA \\
\hline 111 & Pirua & AAA & 1.91 & $3 x$ & ++ & & & AAA & AAA \\
\hline 112 & Pagatow & AAA & 1.91 & $3 x$ & ++ & & & AAA & AAA \\
\hline 113 & Ouro Mel & AAA & 1.92 & $3 x$ & ++ & & & AAA & AAA \\
\hline 114 & Orotawa & AAA & 1.93 & $3 x$ & ++ & & & AAA & AAA \\
\hline 115 & Nanicão & AAA & 1.94 & $3 x$ & ++ & & & AAA & AAA \\
\hline 116 & Nam & AAA & 1.94 & $3 x$ & ++ & & & AAA & AAA \\
\hline 117 & Muga & AAA & M & $?$ & ++ & & & $A ?$ & AAA \\
\hline 118 & Morong & AAA & 1.92 & $3 x$ & ++ & & & AAA & AAA \\
\hline 119 & Markatooa & AAA & 1.91 & $3 x$ & ++ & & & AAA & AAA \\
\hline 120 & Maida & AAA & 1.94 & $3 x$ & ++ & & & AAA & AAA \\
\hline 121 & Leite & AAA & 1.93 & $3 x$ & ++ & & & AAA & AAA \\
\hline 122 & Lacatan & AAA & 1.90 & $3 x$ & ++ & & & AAA & AAA \\
\hline 123 & Azedinha & $A A B$ & 2.36 & $4 x$ & ++ & + & + & $A A A B$ & AAAB \\
\hline 124 & Imperial & AAA & 1.93 & $3 x$ & ++ & & & AAA & AAA \\
\hline
\end{tabular}


Table 1 Musa accessions from the ex situ collection of 'Embrapa Mandioca Fruticultura' Center (Cruz das Almas, Brazil) with information from passport data, and characterization of genomic constitution by flow cytometry, PCR-RFLP of internal transcribed spacers (ITS) regions, and Simple Sequence Region (SSR) loci (Continued)

\begin{tabular}{|c|c|c|c|c|c|c|c|}
\hline 125 & Highgate & AAA & 1.91 & $3 x$ & ++ & AAA & AAA \\
\hline 126 & Gros Michel & AAA & 1.94 & $3 x$ & ++ & AAA & AAA \\
\hline 127 & Grande Naine & AAA & 1.92 & $3 x$ & ++ & AAA & AAA \\
\hline 128 & Dois Cachos & AAA & 1.91 & $3 x$ & ++ & AAA & AAA \\
\hline 129 & Dodoga & AAA & 1.94 & $3 x$ & ++ & AAA & AAA \\
\hline 130 & Cocos & AAA & 1.95 & $3 x$ & ++ & AAA & AAA \\
\hline 131 & Caru Verde & AAA & 1.96 & $3 x$ & ++ & AAA & AAA \\
\hline 132 & Caru Roxa & AAA & 1.95 & $3 x$ & ++ & AAA & AAA \\
\hline 133 & Canela & AAA & 1.94 & $3 x$ & ++ & AAA & AAA \\
\hline 134 & Bakar & AAA & 1.91 & $3 x$ & ++ & AAA & AAA \\
\hline 135 & Bagul & AAA & 1.93 & $3 x$ & ++ & AAA & AAA \\
\hline 136 & Amritsagar & AAA & 1.93 & $3 x$ & ++ & AAA & AAA \\
\hline 137 & Ambei & AAA & 1.94 & $3 x$ & ++ & AAA & AAA \\
\hline 138 & AAA Desconhecida & AAA & 1.93 & $3 x$ & ++ & AAA & AAA/AAB \\
\hline 139 & Zebrinha & $\mathrm{AA}(\mathrm{W})$ & 1.23 & $2 x$ & ++ & AA & $\mathrm{AA}$ \\
\hline 140 & Selangor & $\mathrm{AA}(\mathrm{W})$ & 1.25 & $2 x$ & ++ & AA & AA \\
\hline 141 & Perak & $\mathrm{AA}(\mathrm{W})$ & 1.26 & $2 x$ & ++ & AA & $\mathrm{AA}$ \\
\hline 142 & Pa Songkla & $\mathrm{AA}(\mathrm{W})$ & 1.23 & $2 x$ & ++ & AA & $\mathrm{AA}$ \\
\hline 143 & Pa Rayong & $\mathrm{AA}(\mathrm{W})$ & 1.26 & $2 x$ & ++ & $\mathrm{AA}$ & AA \\
\hline 144 & Pa Phatthalung & $\mathrm{AA}(\mathrm{W})$ & 1.23 & $2 x$ & ++ & $\mathrm{AA}$ & $\mathrm{AA}$ \\
\hline 145 & Pa Musore 3 & $\mathrm{AA}(\mathrm{W})$ & 1.25 & $2 x$ & ++ & $\mathrm{AA}$ & AA \\
\hline 146 & Pa Musore 2 & $\mathrm{AA}(\mathrm{W})$ & 1.27 & $2 x$ & ++ & AA & $\mathrm{AA}$ \\
\hline 147 & Pa Abissinea & $\mathrm{AA}(\mathrm{W})$ & 1.28 & $2 x$ & ++ & AA & AA \\
\hline 148 & N.118 & $\mathrm{AA}(\mathrm{W})$ & 1.29 & $2 x$ & ++ & AA & AA \\
\hline 149 & Monyet & $\mathrm{AA}(\mathrm{W})$ & 1.23 & $2 x$ & ++ & AA & AA \\
\hline 150 & Modok Gier & $\mathrm{AA}(\mathrm{W})$ & 1.25 & $2 x$ & ++ & AA & $\mathrm{AA}$ \\
\hline 151 & Microcarpa & $\mathrm{AA}(\mathrm{W})$ & 1.26 & $2 x$ & ++ & $\mathrm{AA}$ & $\mathrm{AA}$ \\
\hline 152 & Malaccensis & $\mathrm{AA}(\mathrm{W})$ & 1.23 & $2 x$ & ++ & $\mathrm{AA}$ & AA \\
\hline 153 & Krasan Saichon & $\mathrm{AA}(\mathrm{W})$ & 1.22 & $2 x$ & ++ & $\mathrm{AA}$ & $\mathrm{AA}$ \\
\hline 154 & Khae & $\mathrm{AA}(\mathrm{W})$ & 1.28 & $2 x$ & ++ & AA & AA \\
\hline 155 & Jambi & $\mathrm{AA}(\mathrm{W})$ & 1.27 & $2 x$ & ++ & $\mathrm{AA}$ & $\mathrm{AA}$ \\
\hline 156 & Cici & $\mathrm{AA}(\mathrm{W})$ & 1.24 & $2 x$ & ++ & $\mathrm{AA}$ & AA \\
\hline 157 & Calcutta 4 & $\mathrm{AA}(\mathrm{W})$ & 1.23 & $2 x$ & ++ & AA & AA \\
\hline 158 & Burmannica & $\mathrm{AA}(\mathrm{W})$ & 1.23 & $2 x$ & ++ & $\mathrm{AA}$ & $\mathrm{AA}$ \\
\hline 159 & Buintenzorg & $\mathrm{AA}(\mathrm{W})$ & 1.27 & $2 x$ & ++ & $\mathrm{AA}$ & $\mathrm{AA}$ \\
\hline 160 & Birmanie & $\mathrm{AA}(\mathrm{W})$ & 1.28 & $2 x$ & ++ & AA & AA \\
\hline 161 & M 61 & $\mathrm{AA}(\mathrm{H})$ & 1.23 & $2 x$ & ++ & $\mathrm{AA}$ & AA \\
\hline 162 & M 53 & $\mathrm{AA}(\mathrm{H})$ & 1.27 & $2 x$ & ++ & AA & AA \\
\hline 163 & M 48 & $\mathrm{AA}(\mathrm{H})$ & 1.28 & $2 x$ & ++ & $\mathrm{AA}$ & AA \\
\hline 164 & F3P4 & $\mathrm{AA}(\mathrm{H})$ & 1.23 & $2 x$ & ++ & AA & AA \\
\hline 165 & $\mathrm{~F} 2 \mathrm{P} 2$ & $\mathrm{AA}(\mathrm{H})$ & 1.25 & $2 x$ & ++ & AA & $\mathrm{AA}$ \\
\hline 166 & Tuugia & $\mathrm{AA}(\mathrm{C})$ & 1.28 & $2 x$ & ++ & $\mathrm{AA}$ & $\mathrm{AA}$ \\
\hline
\end{tabular}


Table 1 Musa accessions from the ex situ collection of 'Embrapa Mandioca Fruticultura' Center (Cruz das Almas, Brazil) with information from passport data, and characterization of genomic constitution by flow cytometry, PCR-RFLP of internal transcribed spacers (ITS) regions, and Simple Sequence Region (SSR) loci (Continued)

\begin{tabular}{|c|c|c|c|c|c|c|c|c|c|}
\hline 167 & Tongat & $\mathrm{AA}(\mathrm{C})$ & 1.23 & $2 x$ & ++ & & & $\mathrm{AA}$ & AA \\
\hline 168 & Giral & $A A B$ & 1.90 & $3 x$ & ++ & + & + & $A A B$ & $A A B$ \\
\hline 169 & Tjau Lagada & $\mathrm{AA}(\mathrm{C})$ & 1.23 & $2 x$ & ++ & & & AA & $\mathrm{AA}$ \\
\hline 170 & Thong Dok Mak & $\mathrm{AA}(\mathrm{C})$ & 1.24 & $2 x$ & ++ & & & AA & AA \\
\hline 171 & TA & $\mathrm{AA}(\mathrm{C})$ & 1.24 & $2 x$ & ++ & & & AA & $\mathrm{AA}$ \\
\hline 172 & Sowmuk & $\mathrm{AA}(\mathrm{C})$ & 1.26 & $2 x$ & ++ & & & AA & AA \\
\hline 173 & SA & $\mathrm{AA}(\mathrm{C})$ & 1.23 & $2 x$ & ++ & & & $\mathrm{AA}$ & AA \\
\hline 174 & S/N. 2 & $\mathrm{AA}(\mathrm{C})$ & 1.25 & $2 x$ & ++ & & & AA & $\mathrm{AA}$ \\
\hline 175 & Raja Uter & $\mathrm{AA}(\mathrm{C})$ & 1.25 & $2 x$ & ++ & & & AA & AA \\
\hline 176 & Pipit & $\mathrm{AA}(\mathrm{C})$ & 1.28 & $2 x$ & ++ & & & AA & AA \\
\hline 177 & Ouro & $\mathrm{AA}(\mathrm{C})$ & 1.23 & $2 x$ & ++ & & & AA & $\mathrm{AA}$ \\
\hline 178 & Niyarma Yik & $\mathrm{AA}(\mathrm{C})$ & 1.28 & $2 x$ & ++ & & & $\mathrm{AA}$ & $\mathrm{AA}$ \\
\hline 179 & NBF 9 & $\mathrm{AA}(\mathrm{C})$ & 1.27 & $2 x$ & ++ & & & AA & AA \\
\hline 180 & NBA 14 & $A A(C)$ & 1.23 & $2 x$ & ++ & & & AA & $\mathrm{AA}$ \\
\hline 181 & Mangana & $\mathrm{AA}(\mathrm{C})$ & 1.23 & $2 x$ & ++ & & & AA & AA \\
\hline 182 & Mambee Thu & $\mathrm{AA}(\mathrm{C})$ & 1.27 & $2 x$ & ++ & & & $\mathrm{AA}$ & $\mathrm{AA}$ \\
\hline 183 & Malbut & $A A(C)$ & M & $?$ & ++ & & & $A A ?$ & $\mathrm{AA}$ \\
\hline 184 & Lidi & $\mathrm{AA}(\mathrm{C})$ & 1.27 & $2 x$ & ++ & & & AA & AA \\
\hline 185 & Khi Maeo & $\mathrm{AA}(\mathrm{C})$ & 1.27 & $2 x$ & ++ & & & $\mathrm{AA}$ & $\mathrm{AA}$ \\
\hline 186 & Khai Nai On & $\mathrm{AA}(\mathrm{C})$ & 1.27 & $2 x$ & ++ & & & AA & AA \\
\hline 187 & Khai & $A A(C)$ & 1.23 & $2 x$ & ++ & & & $\mathrm{AA}$ & AA \\
\hline 188 & Jari Buaya & $\mathrm{AA}(\mathrm{C})$ & 1.25 & $2 x$ & ++ & & & AA & AA \\
\hline 189 & Jaran & $\mathrm{AA}(\mathrm{C})$ & 1.26 & $2 x$ & ++ & & & AA & $\mathrm{AA}$ \\
\hline 190 & Fako Fako & $\mathrm{AA}(\mathrm{C})$ & 1.28 & $2 x$ & ++ & & & AA & AA \\
\hline 191 & Berlin & $\mathrm{AA}(\mathrm{C})$ & 1.23 & $2 x$ & ++ & & & AA & AA \\
\hline 192 & Babi Yadefana & $\mathrm{AA}(\mathrm{C})$ & 1.26 & $2 x$ & ++ & & & $\mathrm{AA}$ & $\mathrm{AA}$ \\
\hline 193 & Prata Manteiga & $A A B$ & 1.92 & $3 x$ & ++ & & & $A A B$ & $A A B$ \\
\hline 194 & Borneo & $\mathrm{AA}(\mathrm{W})$ & 1.25 & $2 x$ & ++ & & & $\mathrm{AA}$ & $\mathrm{AA}$ \\
\hline 195 & Madu & AA & 1.28 & $2 x$ & ++ & ++ & + & $A B ?$ & AA \\
\hline 196 & Prata Maçã & $\mathrm{AAAB}$ & 2.46 & $4 x$ & ++ & + & + & $A A A B$ & $\mathrm{AAAB}$ \\
\hline 197 & Verde & $A A B$ & 1.90 & $3 x$ & ++ & + & + & $A A B$ & $A A B$ \\
\hline 198 & Prata Anã 2 & $A A B$ & 1.90 & $3 x$ & ++ & + & + & $A A B$ & $A A B$ \\
\hline 199 & Prata Anã 3 & $A A B$ & 1.91 & $3 x$ & ++ & + & + & $A A B$ & $A A B$ \\
\hline 200 & Pacovan Ken-? & AAAB & 2.46 & $4 x$ & ++ & + & + & AAAB & AAAB \\
\hline 201 & Pitogo & $A B B$ & 1.24 & $2 x$ & ++ & ++ & ++ & $A B ?$ & $A B B$ \\
\hline 202 & Pacha Nadan & $A B$ & 1.97 & $3 x$ & ++ & + & + & $A A B$ & $A A B$ \\
\hline 203 & Njok Kon & $A A B$ & 1.94 & $3 x$ & ++ & ++ & ++ & $A B B$ & $A B B$ \\
\hline 204 & Marmelo & ${ }^{\mathrm{y}} \mathrm{NI}$ & 1.25 & $2 x$ & ++ & ++ & ++ & $A B ?$ & $A B B$ \\
\hline 205 & Lareina BT100 & ${ }^{\mathrm{y}} \mathrm{NI}$ & 1.30 & $2 x$ & ++ & & & AA & AAA/AAAA \\
\hline 206 & Pisang Ceylan & $A A B$ & $?$ & $?$ & ++ & + & + & $A A B$ & $A A B$ \\
\hline 207 & Pisang Nangka & AA & 1.28 & $2 x$ & ++ & & & AA & $A A B$ \\
\hline 208 & Willians & AAA & 1.92 & $3 x$ & ++ & & & AAA & AAA \\
\hline
\end{tabular}


Table 1 Musa accessions from the ex situ collection of 'Embrapa Mandioca Fruticultura' Center (Cruz das Almas, Brazil) with information from passport data, and characterization of genomic constitution by flow cytometry, PCR-RFLP of internal transcribed spacers (ITS) regions, and Simple Sequence Region (SSR) loci (Continued)

\begin{tabular}{|c|c|c|c|c|c|c|c|c|c|}
\hline 209 & PV42-114 & AAAB & 2.28 & $4 x$ & ++ & & & $A A A B$ & $A A A B$ \\
\hline 210 & PV03-76 & $A A A B$ & 2.29 & $4 x$ & ++ & & & $A A A B$ & $A A A B$ \\
\hline 211 & Khae Prae & $\mathrm{AA}$ & 1.23 & $2 x$ & ++ & & & $\mathrm{AA}$ & $\mathrm{AA}$ \\
\hline 212 & Pitu & AA & 1.23 & $2 x$ & ++ & & & AA & AA \\
\hline 213 & Paka IV & AA & 1.26 & $2 x$ & ++ & & & $\mathrm{AA}$ & AA \\
\hline 214 & Ido 110 & AA & 1.28 & $2 x$ & ++ & & & AA & AA \\
\hline 215 & P.Kermain & $\mathrm{Nl}$ & 1.23 & $2 x$ & ++ & & & $\mathrm{AA}$ & $\mathrm{AA}$ \\
\hline 216 & P.Serum & AA & 1.24 & $2 x$ & ++ & & & AA & $\mathrm{AA}$ \\
\hline 217 & Pisang Mas & $\mathrm{AA}$ & 1.25 & $2 x$ & ++ & & & AA & AA \\
\hline 218 & Uw Ati & $\mathrm{AA}$ & $?$ & $?$ & ++ & & & $A A ?$ & $\mathrm{AA}$ \\
\hline 219 & Diplóide Bélgica & AA & 1.24 & $2 x$ & & ++ & ++ & BB & BB \\
\hline 220 & BB França & BB & 1.27 & $2 x$ & & ++ & ++ & BB & BB \\
\hline 221 & $B B \mid A C$ & BB & 1.28 & $2 x$ & & ++ & ++ & BB & BB \\
\hline 222 & Musa laterita & Musa & 1.28 & $2 x$ & ++ & & & - & - \\
\hline 223 & Tambi & AAA & 1.92 & $3 x$ & ++ & & & AAA & AAA \\
\hline \multirow[t]{4}{*}{224} & Musa royal & Musa & 1.27 & $2 x$ & ++ & ++ & & - & - \\
\hline & Minimal CV (\%) & & 1.23 & & & & & & \\
\hline & Maximum CV (\%) & & 4.56 & & & & & & \\
\hline & Mean CV (\%) & & 3.31 & & & & & & \\
\hline
\end{tabular}

++ fragment with strong signal; +: fragment with weak signal.

zInformation based on the Musa MGIS database [42]

${ }^{\mathrm{N}} \mathrm{Nl}$ : No information.

${ }^{\mathrm{X}}$ M: Mixoploidy; C: cultivated; W: wild; H: hybrid.

${ }^{w}$ ?: undefined name or ploidy, or unresolved genomic constitution.

${ }^{\vee}$ Genome composition based on groups formed based on clustering analysis derived from SSR data (Figure 3).

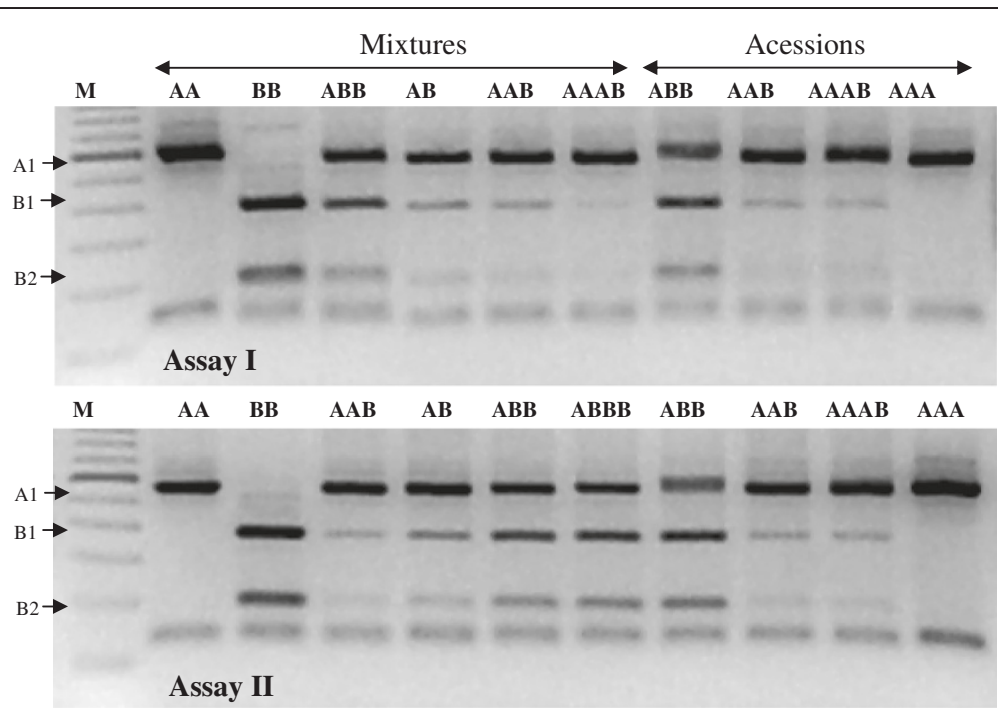

Figure 1 Restriction profiles of the amplified ITS regions (negative picture). Assays to verify competition between doses of the $A$ and/or $B$ genomes for amplification and digestion of a rDNA region in Musa. Assay I: AA (1AA:OBB); BB (OAA:1BB); ABB (1AA:2BB); $A B$ (1AA:1BB); $A A B$ (2AA:1BB); AAAB (3AA:1BB); ABB, AAB; AAAB; AA. Assay II: AA (1AA:0BB); BB (0AA:1BB); AAB (2AA:1BB); AB (1AA:1BB); ABB (1AA:2BB); ABBB (1AA:3BB); ABB; $A A B ; A A A B ; A A$. M: 100 bp ladder. 
of fragments $(\mathrm{Na})$ and the fraction of polymorphic bands ( $\beta=$ number of polymorphic bands/total number of bands) [51]. To compare diploids, the PIC and mean heterozygosity (Ho) were estimated using PowerMarker v3.25 [52].

Two approaches were adopted to investigate the genetic structure and diversity among the accessions. In the first case, polymorphisms were treated as binary data (presence or absence). The binary data were then used to obtain a dissimilarity matrix using the Jaccard index employing the software Genes [53]. The matrix was used to run a cluster analysis based on Neighbor-joining [54] using Mega 4.0 [55]. To determine the genetic structure among accessions, a second approach based on the co-dominant nature of the marker was adopted using the Bayesian method implemented using the software Structure 2.3.2, assuming that some fraction of the genome of each individual came from $\mathrm{k}$ populations, characterized by their allelic frequencies [31,56]. The input file was prepared accordingly to multiple ploidies [32] with adaptations. As the tetraploid accessions revealed a similar pattern of alleles as triploids, with the majority of the loci displaying from 1 to 3 alleles, all accessions were standardized as triploid. For diploid accessions with more than two alleles and triploids with more than three alleles, the locus with excess alleles was removed from the analysis and considered missing. For the triploid and tetraploid accessions revealing only two alleles, it was necessary to consider one allele as duplicated. Two alternative matrices were generated: one considering the smallest allele in terms of base pairs as duplicated, and the other, based on the largest allele, as duplicated in the matrix. In this way, a triploid with the allelic profile $A_{1} A_{2} \quad\left(A_{1}<A_{2}\right)$ was considered either as $A_{1} A_{1} A_{2}$ or $A_{1} A_{2} A_{2}$, creating two files for analysis (Analysis I and Analysis II, respectively). After determining the number of populations $(\mathrm{k})$, the memberships (matrices q) of Analysis I and Analysis II according to Structure were compared by Pearson correlation as proposed by Jing et al. [57]. Thus, a high correlation value between matrices would suggest a similar genetic structure among the approaches.

The origin of the modern banana cultivars involved intra- and interspecific hybridizations, and the mixture model and allelic frequency correlated was adopted. A burn-in of 150,000, followed by 70,000 Monte Carlo Markov Chain, was used for each k, varying from 2 to 30 , with ten runs for each $k$. The choice of the likely number of populations was performed based on the highest log value of the likelihood $(\mathrm{LnP}(\mathrm{K}))$ and using the method developed by Evanno et al. [58].

\section{Results}

\section{Ploidy determination by flow cytometry}

Leaf samples from each accession were analyzed by flow cytometry to determine ploidy, and the $2 \mathrm{C}$ values were estimated in pg (Table 1). The 77 diploid accessions (AA; BB; and Rhodochlamys) presented an average of $2 \mathrm{C}=2 x=1.26 \mathrm{pg}$, ranging from 1.22 to $1.30 \mathrm{pg}$. The 115 triploids (AAA; AAB; or ABB) displayed an average of $2 \mathrm{C}=3 x=1.93 \mathrm{pg}$, varying from 1.86 to $1.99 \mathrm{pg}$, whereas the 23 tetraploid accessions (AAAA or AAAB) had a mean of $2 \mathrm{C}=4 x=2.45 \mathrm{pg}$, ranging from 2.28 to $2.56 \mathrm{pg}$ (Table 1). The overall average M. acuminata genome (A) and $M$. balbisiana (B) was estimated to be $2 \mathrm{C}=1.25 \mathrm{pg}$. The overall coefficient of variation between samples was $3.31 \%$, ranging from 1.23 to $4.56 \%$.

From the 224 accessions evaluated, 221 were from section Musa and three were from section Rhodochlamys. From the Musa section (Table 1; Additional file 1: Table S1), three accessions (204, 205 and 215) had their ploidy defined for the first time, while for another five (54, 80, 123, 201 and 202), the ploidy level was not in agreement with the passport information. For four accessions (56, 102, 206 and 218), it was not possible to determine the ploidy by flow cytometry, whereas five accessions (10,11, 21, 117 and 183) exhibited mixoploidy (Table 1).

Curiously, accessions 201 ('Pitogo') and 204 ('Marmelo'), classified as diploid by flow cytometry, presented a typical ABB profile by ITS PCR-RFLP (compare lanes 7 and 8, top panel Figure 2). Both accessions were grouped as ABB in the clustering and Structure analyses (Figure 3 and 4 below).

\section{Characterization of the genomic constitution based on ITS-PCR-RFLP}

To evaluate whether the method proposed by Nwakanma et al. [20] would enable the discrimination of genomic constitution and ploidy, preliminary assays were carried out using mixtures of DNA samples from the $M$. acuminata ('Calcutta 4') and M. balbisiana ('Butuhan') genomes to obtain various artificial combinations of genomes, mimicking the natural ones. In the first assay, an increase in genome dose revealed more intense B-specific bands (350 and $180 \mathrm{bp}$ ) for BB, followed by $\mathrm{ABB}, \mathrm{AB}, \mathrm{AAB}$ and $\mathrm{AAAB}$ (Figure 1; Assay I). A clear distinction between genome composition was possible for $\mathrm{BB}, \mathrm{ABB}$ and $\mathrm{AB}$, but not between $\mathrm{AAB}$ and AAAB. Similarly, no clear difference between the reference genomes 'Prata Anã' (53; $\mathrm{AAB}$ ) and 'BRS Platina' (84; $\mathrm{AAAB}$ ) was detected (Figure 1). In the second assay, the increasing dose of the $B$ genome did not allow the discrimination between $\mathrm{ABB}$ and $\mathrm{ABBB}$ (Figure 1; Assay II), but both differed from $A A B$ and $A B$ in the band intensity pattern. Thus, this simulation demonstrated the possibility of 


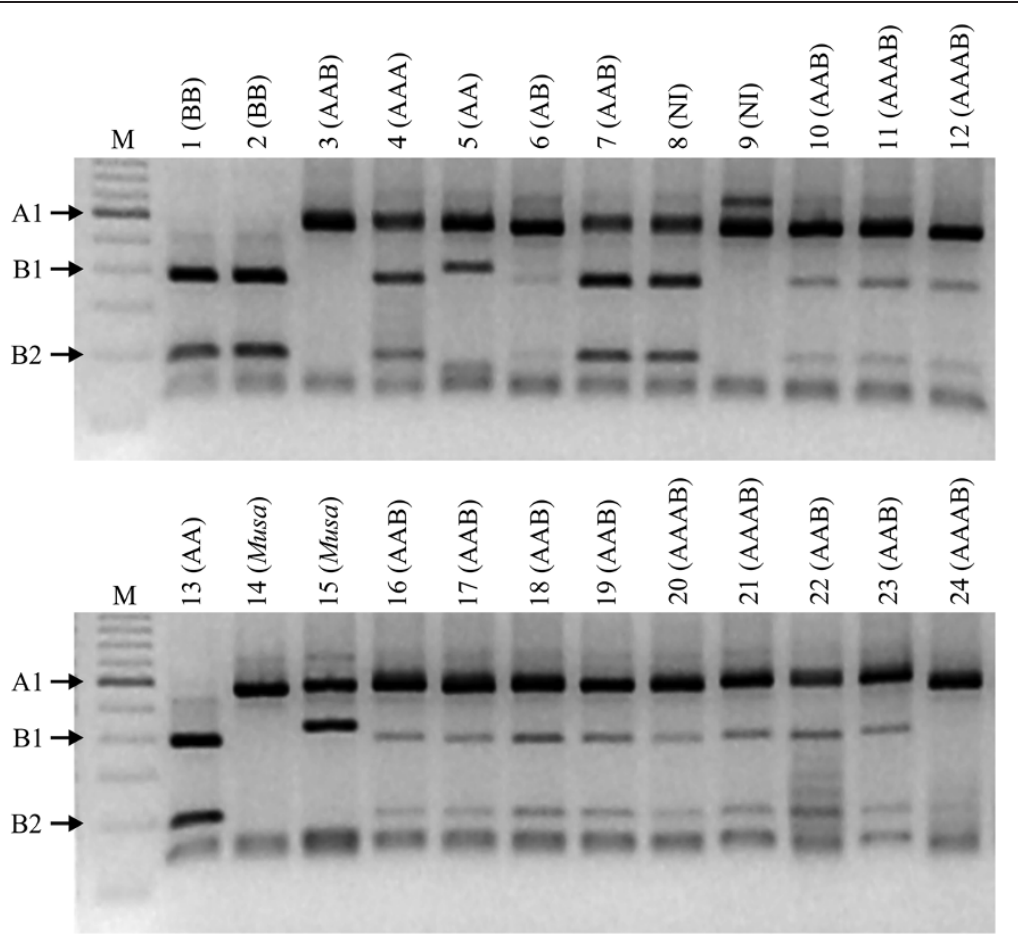

Figure 2 Restriction profile of the amplified ITS regions from Musa accessions with distinct genomic composition. Amplification products of the ITS1-5.8S-ITS2 region after digestion with Rsal. Accessions 1: 'Butuhan'; 2: BB'Panamá'; 3: 'Figue Rose Naine'; 4: 'Tugoomomboo'; 5: 'Madu'; 6: 'PachaNadan'; 7: 'Njok Kon'; 8:'Marmelo'; 9: 'Lareina BT100'; 10: 'PisangCeylan'; 11:'PV42-114'; 12:'PV03-76'; 13: 'Diplóide Bélgica'; 14:Musa laterita; 15: 'Musa Royal' (M. ornata x M. velutina); 16:'Prata Ponta Aparada'; 17:'Chifre Vaca'; 18: 'Pulut'; 19: 'Pratão'; 20:'Pacovan Ken'; 21:'Garantida'; 22: 'Kelat'; 23:'Java IAC'; 24: 'BRS Tropical'. Genomic composition determined by morphology is between parentheses. NI no information on genome composition; (Musa): accession from Rhodochlamys; M: 100 bp ladder marker. Arrows point to fragments of 530 bp specific for A genome (A1); 350 and 180 bp specific for the B genome (B1 and B2).

genome constitution discrimination for accessions when the ploidy level had been previously determined.

Amplification of the ITS regions produced a fragment of $\sim 700$ bp from all 224 accessions and disclosed the expected fragments that characterized the presence of genome $\mathrm{A}$ and/or $\mathrm{B}$ after digestion with RsaI (Figure 2). From the 224 accessions evaluated, three accessions without previous information (204, 205 and 215) had their genomic constitution defined, while 13 (5.8\%) disagreed with the information available about genomic constitution defined based on previous published or characterized by morphological descriptors, including accessions 7, 10, 11, 28, 68, 72, 79, 102, 195, 201, 202, 203, and 219 (Table 1). But from these 13 accessions, only four (28, 79, 102 and 195) appeared to truly demonstrate inconsistencies for the genomic constitutions established by PCR-RFLP. Accessions 28 ('Yangambi $n^{\text {o. } 2 ' ; ~ A A B) ~ a n d ~} 79$ ('BRS Tropical'; AAAB) did not exhibit the B-specific $350 \mathrm{bp}$ fragment upon digestion, while 102 ('Tugoomomboo'; AAA) displayed a typical ABB digestion pattern, and accession 195 ('Madu'; AA) presented a slight deviation in size of the B-specific fragment. By clustering analysis derived from SSR genotyping (see below), genomic constitution for accessions 28,
79, 102 and 195 were confirmed as AAB, AAAB, AAB, and AA, respectively.

For the Musa ornamental diploid species represented by $M$. basjoo (accession 1; Table 1) and the hybrid 'Royal' (224), derived from a cross between two species of the section Rhodochlamys ( $M$. ornata x M. velutina) [59], a slightly larger fragment than the 350 bp from M. balbisiana and the $530 \mathrm{bp}$ from the M. acuminata fragment were observed. For $M$. laterita (222; section Rhodochlamys), only the typical M. acuminata 530 bp fragment was detected (Figure 2; Table 1).

\section{SSR and genetic diversity analyses}

Of the 21 loci tested, only five (MaOCEN09; Mb1-69; Mb1-134; Mb1-139; and AGMI24-25) failed to amplify consistently, while sixteen SSR loci successfully amplified 182 alleles from the 224 accessions, with an average of 11.5 alleles per locus and a range from 7 to 15 alleles (Additional file 1: Table S2). The discriminatory power of each locus was evaluated by estimating the Polymorphic Information Content (PIC) and the Marker Index (MI). To estimate the PIC, the microsatellite data were converted into a binary format (presence or absence of bands), and therefore, the maximum PIC 


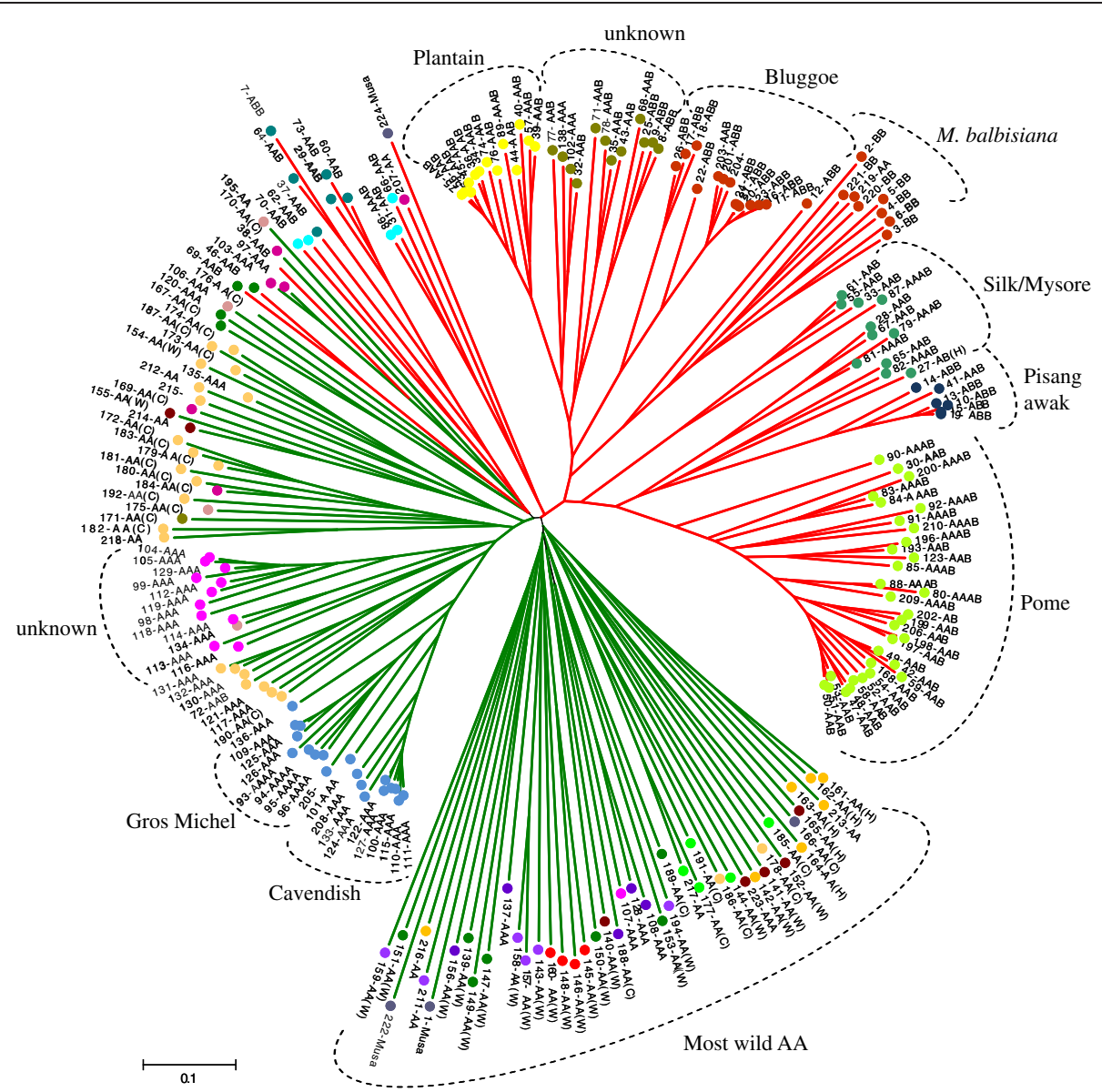

Figure 3 Phenogram demonstrating the genetic relationships among 224 accessions from the ex-situ conservation collection of 'Embrapa Mandioca Fruticultura' Center based on 16 SSR loci, obtained using Neighbor-joining clustering from Jaccard dissimilarity index. Genomic composition based on passport data was included. Full circle colors are related to Figure 6 . Accessions containing A genome from M. acuminata are shown in green branch line and with B genome from $M$. balbisina in red branch line.

could be 0.5 . The average PIC over 16 loci was 0.20 , ranging from 0.16 to 0.30 per locus, indicating a large discriminatory power for the analyzed loci (Additional file 1: Table S2). The MI [51,60] ranged from 1.57 for MaOCENO3 to 3.24 for MaC-CENO4, with an average of 2.28. Considering the mean value of 2.28 as a reference, seven loci (Ma1-17; AGMI 93/94; MaOCENO1; MaOCEN10; MaOCEN14; MaOCEN19; and MaC-CENO4) revealed more diversity in the banana (Additional file 1: Table S2).

Overall, regardless of ploidy, there was a predominance of accessions with two alleles (35.2 to 55.8\%), followed by those with one (14.1\% to $60.7 \%)$; three (3.5 to $32.8 \%$ ); and only a small fraction with four alleles (0.3 to 15.6\%) (Table 2). BB and ABB were the groups with the largest proportion of accessions displaying a single allele $(60.7 \%$ and $41.9 \%$, respectively), followed by wild (41.3\%) and cultivated AA diploids (39.7\%). A small fraction of diploid accessions revealed three alleles in cultivated AA (4.2\%), BB (4.1\%) and wild AA (3.5\%).
Accessions with three alleles predominated in triploids (ranging from $18.3 \%$ for $\mathrm{AAB}$ to $24.3 \%$ for $\mathrm{AAA}$ ) and tetraploids (28.2\% for AAAB and $32.8 \%$ for AAAA). Few accessions revealed four alleles, mostly were tetraploid hybrids AAAA, with $15.6 \%$ of accessions, and AAAB with $3.0 \%$ (Table 2).

The relationship among the 20 most frequent alleles in the cultivated $\mathrm{AA}$ and $\mathrm{BB}$ accessions was investigated in relation to the other genomic and ploidy groups. In general, the most frequent alleles in cultivated AA tended to increase in frequency according to the dose of the A genome (M. acuminata) in the higher ploidy genomic groups (Figure 5A). Similarly, the most frequent alleles in $\mathrm{BB}$ decreased proportionally with the reduction in the dose of the $\mathrm{B}$ genome ( $M$. balbisiana) in the accessions (Figure 5B).

Cultivated diploids displayed higher mean heterozygosity (62.4\%) than the wild diploids (overall average 56.4\%). The lowest mean heterozygosity (37.4\%) was detected among the M. balbisiana accessions (Additional file 1: 


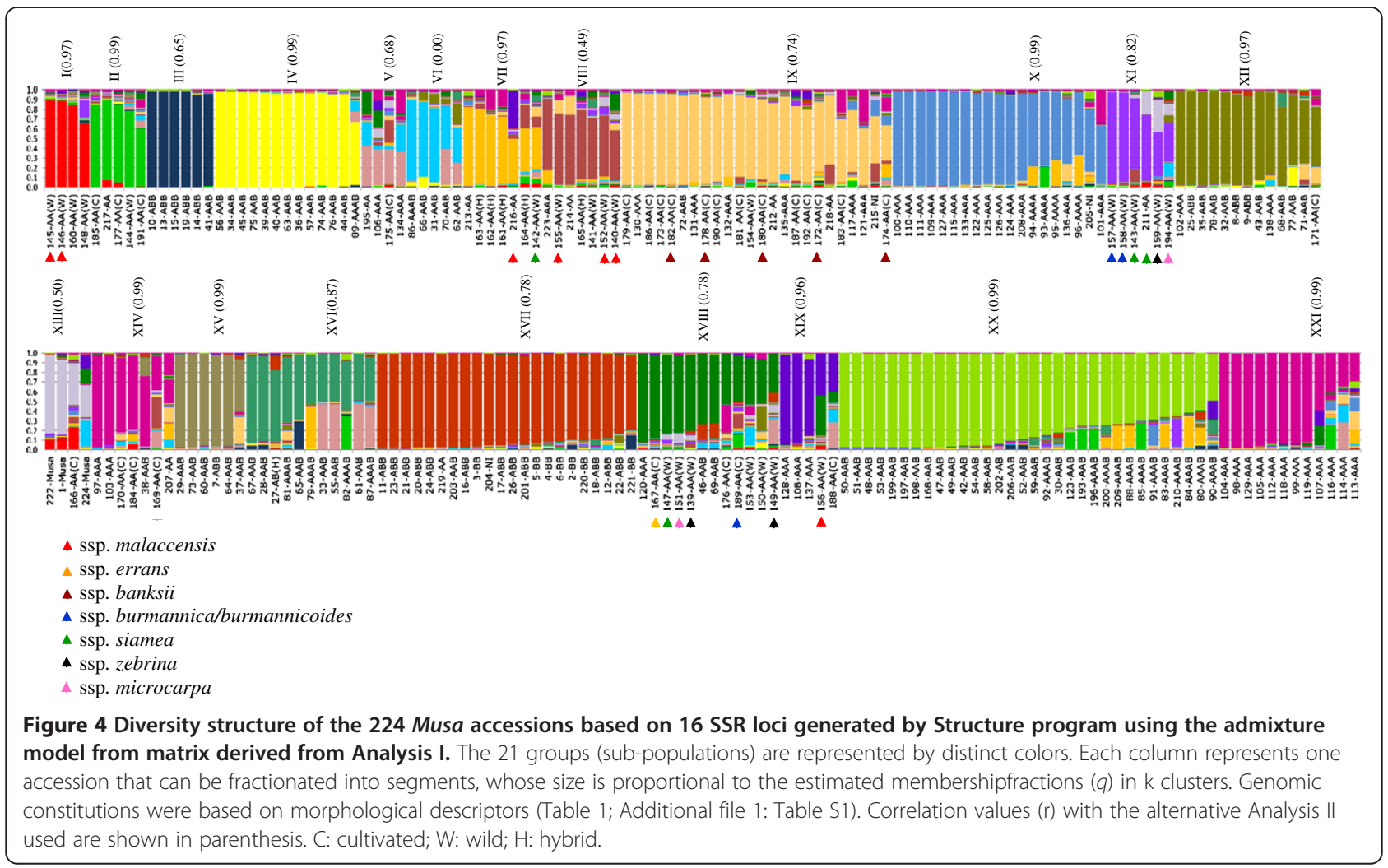

Figure S1), while $M$. acuminata ssp. microcarpa and M. acuminata ssp. burmannica/burmannicoides revealed the largest mean heterozygosity (74\% and $71.9 \%$, respectively). The lowest PIC values were detected for the BB accessions and M. acuminata ssp. banksii with $34.2 \%$ and $36.6 \%$, respectively.

\section{Clustering analyses of the collection}

Clustering analysis based on Neighbor-joining essentially allowed the detection of two major clusters (Figure 3). The first cluster contained accessions with at least one

Table 2 Average ratio (in \%) of accessions per genomic groups, presenting one, two, three or four alleles

\begin{tabular}{cccccccccc}
$\begin{array}{c}\text { No. } \\
\text { alleles }\end{array}$ & BB & AA (W) & AA (C) & AAA & AAB & ABB & AAAB & AAAA \\
\cline { 2 - 9 } & \multicolumn{7}{c}{ (\%) } \\
\hline 1 & 60.7 & 41.3 & 39.7 & 22.7 & 31.7 & 41.9 & 21.8 & 14.1 \\
2 & 35.2 & 54.3 & 55.8 & 52.6 & 48.7 & 39.4 & 47.0 & 37.5 \\
3 & 4.1 & 3.5 & 4.2 & 24.3 & 18.3 & 18.4 & 28.2 & 32.8 \\
4 & 0.0 & 0.9 & 0.3 & 0.5 & 1.3 & 0.3 & 3.0 & 15.6 \\
$\mathbf{n}$ & 8 & 23 & 26 & 43 & 56 & 21 & 16 & 4 \\
$\mathbf{n}_{\mathbf{m}}$ & 7.6 & 21.6 & 24.1 & 42.8 & 51.0 & 20 & 14.6 & 4 \\
\hline
\end{tabular}

${ }^{\mathrm{z}} \mathrm{W}$ : Wild accessions; C: Cultivated; $\mathrm{n}$ : number of samples evaluated; and $\mathrm{n}_{\mathrm{m}}$ : mean number of samples for the evaluated loci. copy of the B genome, while the second one contained those exclusively with the A genome (Figure 3), with the exception of the AAB accessions 38, 46, and 69, allocated together with genome A accessions (Table 1). Similar grouping was obtained by Structure analysis (Figure 4). Within these two main clusters, sub-clusters were formed with accessions according to genome composition and ploidy level. Within the major $\mathrm{A}$ or $\mathrm{AB}$ clusters, the main clusters usually corroborated the classification of subgroups, such as 'Pome' and derived hybrids; 'Plantain'; 'Silk'; 'Pisang awak'; 'Bluggoe'; 'Cavendish'; and 'Gros Michel' (Figure 3). Accessions without previous classification were allocated into the main subgroups, allowing novel categorization, while two sub-clusters (denominated 'unknown' in Figure 3) require further investigations to define proper subgroup classification. Some accessions did not differ for their SSR profiles, possibly representing duplicated accessions (Figure 3), including accessions 45 and 63 from the 'Plantain' subgroup; 15 and 19 from 'Pisang awak' (ABB); 11 and 16, and 20, 21, and 24 from 'Bluggoe' (ABB).

\section{Population structure analysis}

The co-dominant nature of the SSR markers was exploited to analyze the structure of the populations using a Bayesian approach. The number of subpopulations (k) tested ranged between 2 and 30 (Figure 6A). 


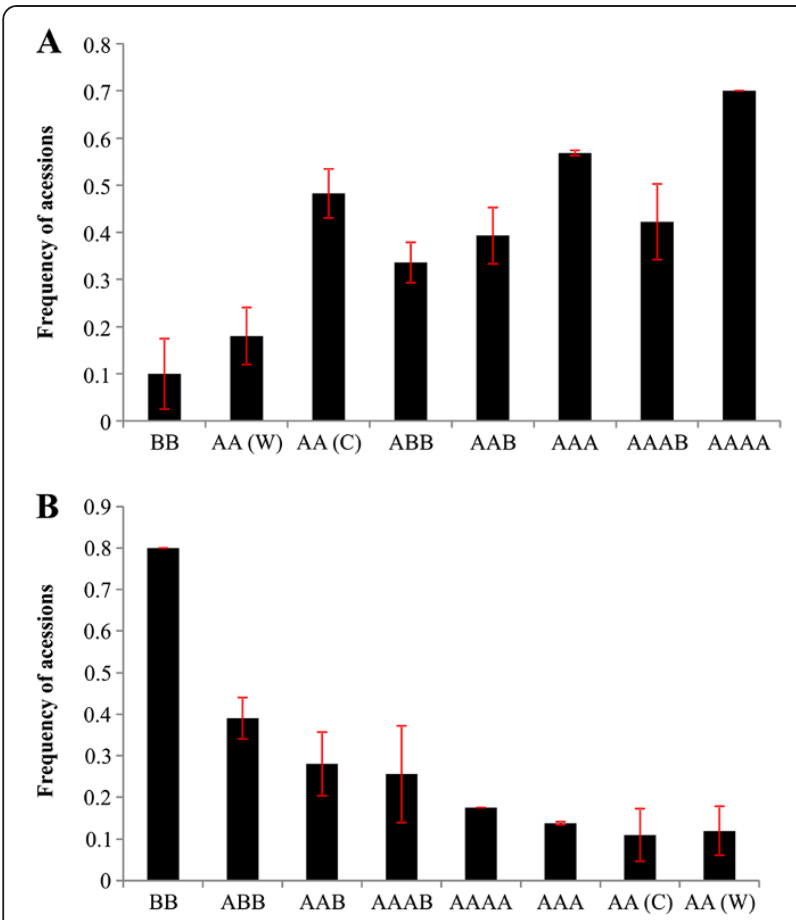

Figure 5 Frequency distribution of the 20 most frequent alleles in cultivated diploid accessions $A A(C)$ (panel $A$ ) and BB (panel B) in comparison with other genomic groups. W: wild; C: cultivated. The errors bars refer to the ratio of accessions that did not amplify one or more analyzed loci.

To estimate the approximate number of subpopulations, the maximum estimated value of the logarithm of likelihood $(\mathrm{LnP}(\mathrm{K}))$ was used. However, for the evaluated accessions, the value for $\operatorname{LnP}(\mathrm{K})$ did not reach a clear plateau, continuing to increase together with the variances between the tested $\mathrm{k}$ (Figure 6A). Under these circumstances, the number of subpopulations $(\mathrm{k})$ was projected to be between 16 and 23 (Figure 6A). For $\mathrm{k}=20,21$ or 22 , there was no large variation for the main groups formed (Figure 6; panels C1, C2 and C3). The method that calculates the second order of likelihood change $(\Delta \mathrm{k})$ is more sensitive than the previous one to detect the number of subpopulations under these circumstances [58]. Adopting this approach, $\Delta \mathrm{k}$ peaked at $\mathrm{k}=21$ (Figure 6B).

The two alternative matrices tested (Analysis I and II) presented little differences for genotype allocation and membership values $(q)$. The Pearson correlations $(r)$ between the two distinct alternative approaches was high and significant $(\mathrm{p} \leq 0.01)$ for most groups $(\mathrm{r}=0.65$ to 0.99), indicating a good adjustment between the coancestries that the alternative matrices generated (not shown), except for group VI, which did not show any correspondence between the two analyses (Figure 4). Therefore, only results from Analysis I (see Methods) was used for the purpose of discussion.
From the 21 groups formed by Structure (Figure 4), five contained only diploid accessions (group I, II, VII, $\mathrm{XI}$, and XIII); six contained triploids or tetraploids (III, $\mathrm{IV}, \mathrm{VI}, \mathrm{XV}, \mathrm{XX}$, and XXI); and the other ten contained mixtures of diploids and triploids with the following (2x:3x/4x) proportion for each group: V (2:2); VIII (6:1); IX (17:7); XII (1:12); XIV (4:3); XVI (1:10); XVII (9:13); XVIII (9:3); and XIX (1:3); and X (1 2x: 14 3x: 4 4x).

The membership value $(q)$ for the 21 subpopulations (224 accessions) varied from 0.24 to 0.60 for 41 accessions; 0.61 to 0.80 for 58 accessions; 0.81 to 0.90 for 33 accessions; and greater than 0.90 for 92 accessions (Figure 7A). The largest frequencies of accessions with higher membership $(0.90<q \leq 0.98)$ were from the genomic groups $\mathrm{ABB}$; $\mathrm{BB}$ and $\mathrm{AAA}$ with $87.5 \%$; $62.5 \%$; and $60.5 \%$, respectively (Figure 7E; D; G). On the other hand, the lowest values of membership ( $q$ varying from 0.24 to 0.50$)$ were observed for the wild AA diploids $[\mathrm{AA}(\mathrm{W})]$, the cultivated diploids $[\mathrm{AA}(\mathrm{C})]$, and $\mathrm{AAAB}$, at $30.4 \%, 23.2 \%$, and $22.2 \%$ of accessions, respectively (Figure 7B; C; I). Accessions from the main banana cultivated subgroups (AAA, $\mathrm{AAB}, \mathrm{ABB}$ ) in general exhibited high membership values (Figure 4), but accessions with admixture $(q \leq 0.90)$ were also encountered, such as 43 , $71,68,77$, and 138 in group XII ('Saba' subgroup); accessions 28, 33, 55, 61, 65, and 67 in group XVI ('Silk'/'Mysore' subgroups); 101, 136 and 208 in group $\mathrm{X}$ ('Cavendish'/'Gros Michel' subgroups); accessions 30, 52, 59, 193, and 206 in group XX ('Pome' subgroup); and 107, 113, 114, and 116 in group XXI. Other triploid accessions with admixture were distributed in groups $\mathrm{V}$; VI; VII; IX; XII; XIV; XV; XVII; and XIX (Figure 4).

Essentially, the triploid/tetraploid groups generated by Structure were identical to the clusters revealed by clustering analysis for the major banana subgroups, such as 'Pisang awak' (group III; Figure 3 and 4); 'Plantain' (group IV); 'Cavendish' and 'Gros Michel' (group X); 'Bluggoe' (group XVII); 'Pome' (group XX), and groups $\mathrm{XV}, \mathrm{XII}$ and XXI with non-categorized accessions (Figure 3 and 4).

Regarding the diploid accessions analyzed by Structure, all eight $M$. balbisiana accessions were placed in subpopulation XVII, together with $12 \mathrm{ABB}$ accessions (80\%) (Figure 4). The M. acuminata subspecies (Additional file 1: Table S1) were distributed into various clusters: ssp. malaccensis with two accessions at group I; one at VII; three at VIII; and one at XIX; ssp. errans with one accession at group XVIII; ssp. banksii with 5 accessions at group IX; spp. burmannica/burmannicoides with two accessions at XI; and one at XVIII; ssp. siamea with one accession at VII; two at XI; and one at XVIII; ssp. zebrina with one accession at XI; and two at XVIII; and ssp. microcarpa with one accession at XI; and two at XVII (Figure 4). 

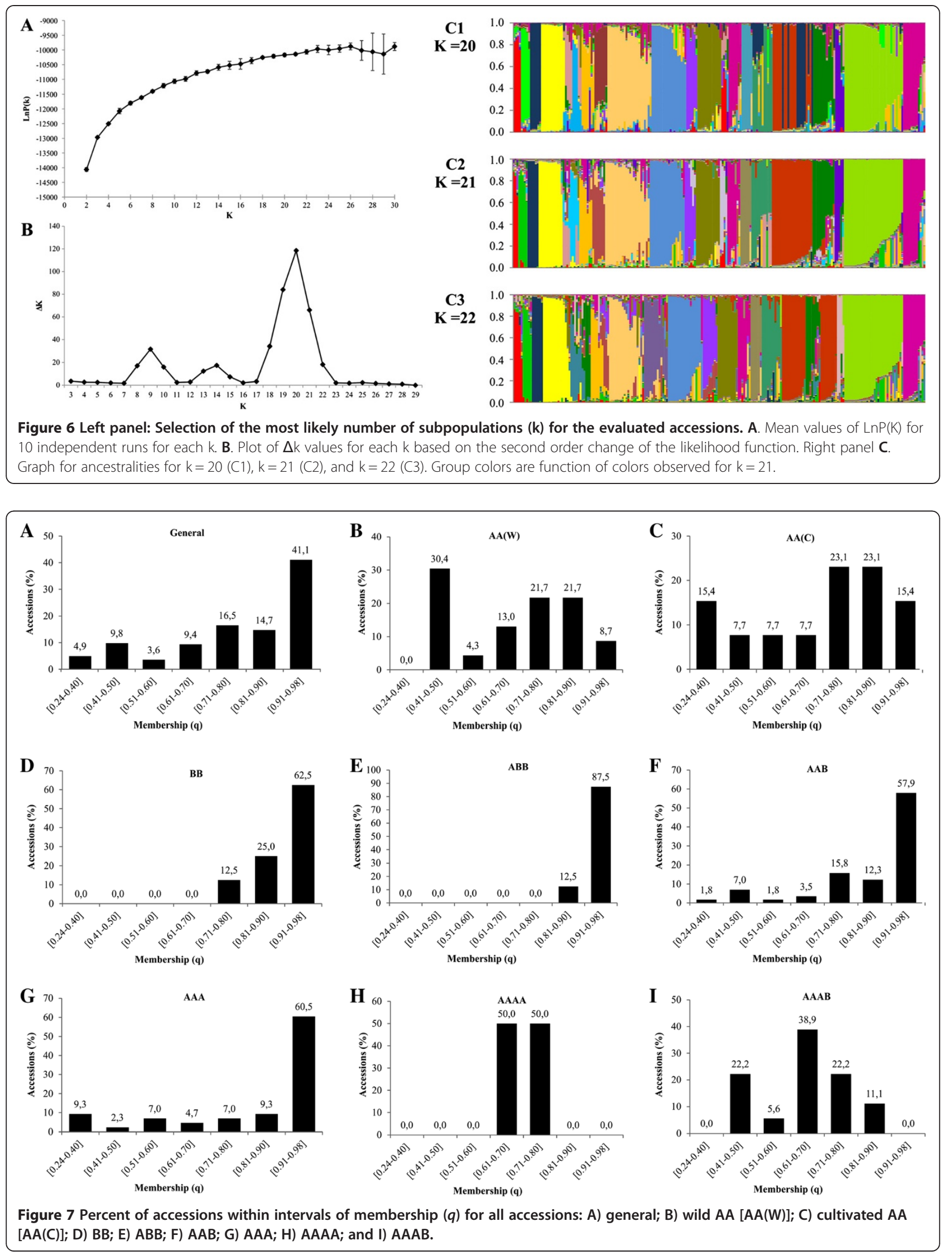
Diploid accessions were highly heterogeneous (mixture), and their ancestry remained restricted to other group of diploids, except for accessions 161, 162, 183 and 195, which exhibited ancestry with group XXI of AAA triploids, and BB 'IAC' (221) with ancestry to group III of the subgroup 'Pisang awak' (ABB) (Figure 4).

\section{Discussion}

\section{Characterization of ploidy and genomic constitution}

Flow cytometry was used to define the genome size $(2 \mathrm{C}$ content) and the ploidy level of 224 accessions. From the 221 section Musa accessions, only five (2.3\%) presented conflicting results with the passport data. Similar discrepancy between estimation of ploidy by morphological characterization and flow cytometry had been reported [61,62]. Previously, it was believed that nuclear DNA content would be a good predictor of genomic constitution [63], as the $\mathrm{BB}$ genome was thought to be on average $12 \%$ smaller than the AA genome [64]. However, in our study the estimated size of genome $\mathrm{A}$ or $\mathrm{B}$ did not differ among the various ploidies and genomic groups, and therefore, estimating $\mathrm{C}$ values by flow cytometry alone could not distinguish the genomic constitution. The predicting value of genomic constitution might be affected by minute differences in the size of individual A and B genomes; variation in the number of sets of chromosomes from distinct genomes in triploids or tetraploids, including the occurrence of aneuploids [65]; the involvement of other Musa genomes, such as the presence of S or T genomes (from $M$. schizocarpa or M. textilis, respectively) in some cultivars [65]; or the lack of additiveness of genome size, caused by recombination, resulting in different proportions of genomes A or B $[66,67]$.

Determination of genomic constitution by molecular markers has long been sought, with attempts to use RAPD [68] or SSR [23,28,47,69,70], but with limited precision to determine the genome dosage. When we evaluated the ITS PCR-RFLP approach using standard cultivars, it was possible to identify all expected digested fragments, except the smallest one $(50 \mathrm{bp})$ reported by Nwakanma et al. [20], which was not predicted by in silico digestion (not shown). Simulating the various A and $\mathrm{B}$ genome constitution and dosages indicated the ability to distinguish most genome combinations ( $B B$, $\mathrm{AAB}, \mathrm{ABB}$ and $\mathrm{AB}$ ); however $\mathrm{AAB}$ could not be distinguished from $\mathrm{AAAB}$, and $\mathrm{ABB}$ could not be distinguished from $A B B B$, possibly because of amplification competition. For successful adoption of this approach, knowledge about ploidy is essential [20]. When the ITS PCR-RFLP approach was applied to the whole collection, the genomic constitution of most of the accessions was congruent with the morphologic classification available, as previously reported [21]. Our data indicated that determination of ploidy and genomic constitution using morphologic descriptors can still be considered reliable and useful in most cases, with few exceptions.

Noteworthy, our study revealed that a few accessions presented unexpected behavior, such as 'Yangambi no.2' (28) and 'BRS Tropical' (79), recognized as AAB and $\mathrm{AAAB}$, respectively, but they exhibited typical AAA and AAAA digestion profiles. These changes in the restriction profiles for 'Yangambi $n^{\circ}$ 2' and 'BRS Tropical' (a tetraploid hybrid from 'Yangambi $\mathrm{n}^{\circ} 2$ ') might have derived from a variant of the $\mathrm{B}$ genome rDNA-locus. Other unusual alleles were identified. For example, 'Tugoomomboo' (102), considered as AAA, exhibited an ABB PCR-RFLP profile, but it was classified as AAB by clustering analysis, suggesting the occurrence of the $B$ genome allele for the ITS regions in one of the A genomes. The diploid AA 'Madu' (195) was indicated to be $A B$, with a slight change in the restriction fragment size for the $B$ genome. This alteration in size was derived from a change in the RsaI restriction site, later confirmed by sequencing (not shown). This accession also exhibited ancestrality from group VI of $\mathrm{AAB}$ and $\mathrm{AAAB}$ and XVIII of AAA/AA/AAB (Figure 4). Such results can be related to the occurrence of recombination between the $\mathrm{A}$ and $\mathrm{B}$ genomes $[5,66,67]$.

Incomplete concerted evolution of ITS sequences observed in Musa hybrids, with the predominance of the original parental alleles, might derive from the absence of sexual reproduction [71]. But the observation of unexpected genotypes, demonstrated by sequence analyses of ITS and ETS regions of rDNA, have pointed to the occurrence of recombination between $\mathrm{A}$ and $\mathrm{B}$ or between $M$. acuminata subspecies genomes [5,20,71]. Homeologue pairing and recombination between $\mathrm{A}$ and $B$ chromosomes have been actually observed in meiosis of triploid hybrid accessions ( $\mathrm{AAB}$ and $\mathrm{ABB}$ ) and an allotetraploid (AABB), and appeared to occur at some frequency $[66,70]$.

Therefore, despite fact that small differences in genome size between $M$. acuminata and $M$. balbisiana are recognized, the occurrence of chromosome recombination and multivalent pairing during meiosis, leading to unbalance genome segregation, could generate a continuum in genome sizes among accessions, overlapping differences and impairing the ability to distinguish genomic constitution, as corroborated by our results and others [61,62]. Similarly, our results from PCR RFLP of ITS sequences pointed to the occurrence of recombinants, with the lack of $B$ alleles in two hybrid accessions ( $\mathrm{AAB}$ and $\mathrm{AAAB}$ ), or the $\mathrm{B}$ genome allele in one of the $\mathrm{A}$ genomes for $\mathrm{A} \mathrm{ABB}$ and $\mathrm{AA}$. Exceptions from the commonly observed incomplete concerted evolution might be associated with the occurrence of sexual reproduction, with meiosis offering the possibility for 
homeologue chromosome pairing generating recombinant chromosomes.

\section{Genetic diversity and clustering analysis}

Sixteen SSR loci were used, revealing 182 alleles, with an average of 11.5, while Christelová et al. [29] detected an average of 15.4 and 14 alleles for 70 diploid and 38 triploid accessions, respectively. Within each ploidy level, the $\mathrm{BB}$ genome group presented a higher proportion of accessions with only one allele (homozygosis) as previously reported [7], suggesting a lower genetic variability [72] or the occurrence of a large number of null alleles among the accessions evaluated. Conversely, in cultivated AA accessions, structural heterozygosity $[9,73]$ might justify larger average heterozygosity (62.4\%), as well as limited fertility $[7,9,73,74]$, in comparison to the wild diploids (mean 56.4\%) (Additional file 1: Figure S1). Previous studies reported heterozygosity of $61 \%$ for cultivated AA and 53\% for wild diploid accessions based on SSR markers [26], and 61\% for cultivated AA and 53\% for wild AA using RFLP markers [7].

In our study, it was verified a high proportion (more than $75 \%$ ) of accessions producing one and two alleles among triploids. Banana triploid cultivars supposedly originated from crosses between non-reduced $2 n$ gamete (restitution of the first or the second division) and reduced $n$ gamete. The formation of non-reduced gametes tends to be higher when two different genomes are involved, such as in the case of $\mathrm{AB}$ or $\mathrm{AA}$ hybrids between subspecies of $M$. acuminata, as in the cultivated diploids $[8,9]$. In the case of triploids, they most likely resulted from crosses between heterozygote diploid individuals, such as the cultivated diploids with non-reduced gametes $(2 n)$ and another individual $(n)$ carrying a similar allele to one found in the other parent. This hypothesis is supported by the finding that the most frequent alleles found in cultivated AA diploids were observed in increasing frequency in triploid and tetraploid accessions, containing increasing dosages of the $M$. acuminata genome (Figure 5A). The association with cultivated diploids is justified by the presence in cultivated triploids and tetraploids of domestication traits, such as parthenocarpy, sterility and pulp yield [9]. Further, Ortiz [75] investigated the occurrence of nonreduced gametes and observed that all genotypes that produced $2 n$ gametes also produced fruits by pathernocarpy. Many cultivated triploids presented the same mitochondrial and chloroplast patterns as the cultivated diploids [2]. The M. acuminata spp. banksii and $M$. a. spp. errans subspecies, characterized as cultivated diploids, are involved in the development of almost all the cultivated diploids and triploids and parthenocarpic cultivars $[2,9,10]$.
Despite the fact that there was a trend of the participation of $\mathrm{AA}(\mathrm{C})$ in some accessions, only 34\% (ABB); 39\% (AAB); $57 \%$ (AAA); 42\% (AAAB); and 70\% (AAAA) of the accessions contained such alleles. This fact reinforces the previous observation from PCR-RFLP, that the origin of cultivated bananas might have involved recombination events (inter- and intraspecific) and backcrosses between species as well as human intervention. Therefore, a cultivar cannot carry the whole allelic complement from a specific genome A or B [66]. On the other hand, $40 \%$ of the alleles present in the eight $\mathrm{BB}$ accessions were not detected on $\mathrm{ABB}$, most likely because there is a larger diversity of $\mathrm{BB}$ in the formation of $\mathrm{ABB}$. Hippolyte et al. [76] also verified a larger diversity in the $B$ genome of interspecific hybrids, such as $\mathrm{ABB}$, than in $\mathrm{BB}$, suggesting an under-representation of the M. balbisinana diversity or the extinction of the parental donor of the B genome in these hybrids. Our study also detected these differences (Additional file 1: Figure S2), but when compared to $\mathrm{BB}, \mathrm{ABB}$ showed to be more uniform ( $q>0.91$ for $62.5 \%$ and $87.5 \%$ of accessions) in the Structure analysis (Figure 7 and 4).

The analysis performed by converting SSR genotyping into binary data and using it to estimate dissimilarities among genotypes revealed a broad genetic variability among Musa accessions (Additional file 1: Table S2). SSR loci enabled the separation of accessions into two major clusters (one with at least one copy of the B genome, and the second with those exclusively with the A genome) and according to genomic constitution. Further subdivision, in general, corroborated the classification into banana subgroups ('Pome,' 'Plantain,' 'Cavendish,' 'Gros Michel,' 'Bluggoe' 'Silk', and 'Pisang awak'). The most diverse accessions were AA diploids and the less diverse were subgroups of commercial interest, such as 'Pome,' 'Plantain,' 'Cavendish,' 'Gros Michel', and 'Bluggoe', corroborating previous studies [21,22,28,29,70,77-79]. Banana subgroups are characterized by genotypes that share similar agronomic and fruit quality traits [22], which are believed to originate from a common ancestor, meaning, one single meiotic event and the total lack of a sexual stage in the evolution of these subgroups [78], which justifies the small genetic differences. However, large morphological differences are observed in the field maintained by asexual propagation [78-80]. Epigenetic regulation might help to elucidate phenotypic differences within subgroups not correlated with genetic differences $[66,76]$.

In addition to the contribution regarding the identification of duplicated accessions, definition of the ploidy level and genomic constitution of the accessions, the cluster analysis based on SSR also enabled us to infer to which subgroup the natural triploid accessions belong, according to their allocation in the phenogram. This is a key aspect because it enabled us to separate accessions with similar agronomic attributes. This information can be used by 
breeding programs to develop hybrids, which requires certain agronomic or qualitative requisites of the subgroups. However, two clusters (identified as 'unknown'; Figure 3) need to be further investigated for proper categorization.

\section{Population structure and genetic relationships of accessions}

To our knowledge, this is the first work to explore the co-dominant nature of the SSR markers in Musa accessions with distinct ploidy levels using the Bayesian model from Structure. Establishing the relationships and evolution of the genomes of modern cultivars, landraces and their wild relatives is of great importance to determine the effect of human intervention on the process of domestication and to understand the geographic dimension of the diversity and the domestication process of wild species [11]. Many species have undergone a long and complex period of domestication and breeding with limited gene flow, it is expected that there is a complex population structure [81,82].

Here, we suggested the separation of 224 accessions into 21 subpopulations (groups) based on the method proposed by Evanno et al. [58]. Such elevated number of groups was expected considering that accessions with different genomic constitution (AA, BB, $\mathrm{ABB}, \mathrm{AAB}$, AAA, AAAA, and AAAB), and from distinct subgroups ('Pome,' 'Plantain,' 'Cavendish,' 'Gros Michel, etc) from the variou genomic groups were analyzed. In general, the grouping by Structure, even considering some alleles missing, was congruent for most groups formed (triploid and tetraploid accessions, especially) in the phenogram generated based on SSRs as dominant markers (without the exclusion of alleles). The agreement between both sets of data showed that the adaptations did not jeopardize the information from the alleles used in the Structure analysis, which also incorporates ancestrality to each group.

There are emerging evidences that the process of evolution of cultivated bananas might have not derived simply by hybridization followed by selection and clonal propagation ("single-step domestication"), but, on occasions, episodes of meiosis, recombination and fertilization might have eventually occurred $[5,66,71]$. In our study, evidence of mixed population ancestry, given by membership value $(\mathrm{q} \leq 90 \%)$ was verified for wild and cultivated diploids, similar to what was observed for tetraploid hybrids from breeding programs. For triploid accessions, there was evidence of admixture $(12.5 \%$ of $\mathrm{ABB}$ accessions; $39.5 \%$ of $\mathrm{AAA}$; and $42.1 \%$ of $\mathrm{AAB}$ ) with ancestry mostly in two, or many groups (with minimal ancestry to each group), suggesting multiple origins and/or the occurrence of recombinations more often than expected. However, accessions from subgroups 'Plantain' (group V),
'Cavendish' and 'Gros Michel (X), and 'Pome' (XX) were highly homogeneous, with a few exceptions.

The subgroup 'Pome' (AAB; group XX; Figure 4) contained the most cultivated accessions in Brazil, and the Embrapa's breding program has focused on the development of tetraploids derived from crosses between a partially fertile cultivated female parent (AAB), producing non-reduced gametes $(2 n)$, with a male diploid pollen-donor (AA), with novel desirable characters, such as disease resistance. Here, all these 'Pome' tetraploid hybrids from Embrapa demonstrated ancestry to the parental diploids 'M53' (Group IV) or 'Calcutta 4' (Group XI). Similar to what was observed for 'Pome' tetraploid hybrids, all the improved AAAA hybrids from 'Gros Michel' (94, 95, and 96) presented ancestry to diploid groups VII or II. In the 'Pome' subgroup (XX), from five triploids inferred as mixture, only 59 and 193 displayed a clear ancestrality to groups XVI and II, respectively. Curiously, 'FHIA-02' (91) is reported to be an AAAA hybrid, from a cross between 'Williams' and the diploid 'SH3393' with characteristics of the 'Cavendish' subgroup [83], but here it presented only $22 \%$ of the genome as 'Cavendish', suggesting to be 'Pome' (Table 1; Figure 3 and 4). Other FHIA hybrids, whose diploid parents were probably not represented in this study displayed ancestry in groups X ('Cavendish'/'Gros Michel'), XVI ('Silk'/'Mysore') and XIX (Figure 4).

'Cavendish' and 'Gros Michel' were separated into two close subgroups in the cluster analysis (Figure 3); however, according to Structure (Figure 4), representative accessions from these subgroups appeared in the same group, most likely because they share common alleles $[2,8]$. Similar results were also observed using RFLP [8], microsatellite [22], and DArT markers [84], while sharing the same cytotype for organellar genomes as shown based on PCR-RFLP [85]. Hippolyte et al. [76] proposed that accessions from subgroup 'Cavendish' and 'Gros Michel' are derived from a common $2 n$ gamete donor, and most likely two different, but genetically close, $n$ donors. Raboin et al. [8] proposed the accessions 'Sa' and 'KhaiNai On' as the probable $n$ gamete donor for 'Gros Michel' subgroups. In our study, two diploids with identical denominations (173 and 186) were allocated to group IX, but only accession 136 ('Amritsagar') from group X ('Cavendish'/'Gros Michel') presented ancestrality $(q \sim 18 \%)$ to group IX, which gives support to the proposed diploid origins of subgroup 'Cavendish' and 'Gros Michel'. In addition, the diploid 'Lareina BT100' (205) was placed in group $\mathrm{X}$ and it could be a potential $2 n$ gamete donor for 'Cavendish' and 'Gros Michel'. Therefore, diploids from group IX and 'Lareina BT100' appeared as potentially related parentals of the 'Cavendish' and 'Gros Michel', which could be used in crossing programs or chromosome manipulations (doubling) to obtain/resynthesize 'Gros Michel'/'Cavendish' hybrids. 
Noteworthy, some $\mathrm{AAB}$ and AAA triploid accessions demonstrated ancestry to other groups, containing other accessions with similar genomic constitution. It is known that some hybrids showed various degree of residual fertility and it is possible that their evolution involved episodes of sexual reproduction, as suggested by the backcross hypothesis [66].

Our results indicated that Structure was efficient in the detection of ancestry of recently developed tetraploid hybrids by breeding programs in Brazil ('Pome') and Jamaica ('Gros Michel') with a defined genealogy, and for some triploid cultivars. However, this approach appeared to be less efficient to detect the ancestry of most of the primeval triploid accessions, which make up the main commercial subgroups ('Pisang awak'; 'Gros Michel'; 'Cavendish'; 'Pome'; 'Plantain'). This absence of detection of ancestry might be explained by a series of hypotheses.

One possibility is that potential parental diploids for the main commercial subgroups were under-represented in the collection, such as demonstrated by the absence of ancestry in diploids groups for some recent tetraploid hybrids developed by FHIA evaluated in this study (Figure 4). Secondly, the long and uncertain evolutionary period that these triploid cultivars went through since they originated might have resulted in changes/mutations in loci, which could result in complete elimination or modification of the alleles in one of the parents. The ability to detect ancestry for recently developed tetraploid hybrids is important evidence supporting this hypothesis. The process of allopolyploidization can lead to activation of retrotransposons; elimination and rearrangements of parental chromosomes [86,87], DNA sequence losses, apparently from the largest parental genome $[66,88]$ and from highly repetitive sequence regions [89]. Such events might have occurred in M. acuminata, with a larger genome $[62,63]$ and more repetitive sequences than M. balbisiana [90]. Thirdly, the limited number of loci used can also be a reason for the lack of precision in identifying the ancestry of commercial accessions, as a large number of loci would increase the chances of finding equivalent alleles in a group of conserved polymorphic loci among the cultivated triploids and the ancestral diploids. For example, other researchers did not find differences between accessions of the 'Cavendish' subgroup [22], but differences between the accessions of this subgroup have been identified here and by Christelová et al. [29], most likely because of the larger number of alleles identified per locus.

The relationship between diploids and $\mathrm{AAB}$ could have been affected by the potential occurrence of recombinations between homeologue chromosomes with distinct structural organization, contributiong to large genetic changes in allopolyploids [88]. Recombinations between the A and B genomes can occur, and it can be frequent in triploid hybrids, while it might lead to unbalanced genome transmission with respect to the parental species [66,67], justifying variations in $\mathrm{AAB}$ genomes, morphological expression of $\mathrm{A}$ and $\mathrm{B}$ characters, and no addictiveness, as hybrids may carry different recombinant $\mathrm{A}$ and $\mathrm{B}$ chomossomes (e.g. $\mathrm{A}^{\mathrm{B}}$ and $\mathrm{B}^{\mathrm{A}}$ ) [66]. Therefore, all these processes, occurring in isolation or combined, especially in $M$. acuminata subspecies can obstruct the inference of ancestry for most of the triploid accessions.

Concerning diploids, the groups formed by clustering analysis presented distinct behavior as to the one observed for the triploid and tetraploid accessions. In the Structure approach, the groups were defined based on the likelihood probability using allelic frequencies that characterize each population [30], making this method more reliable to evaluate the group of individuals. In our study, a limited number of accessions of the distinct subspecies were analyzed (seven accessions of ssp. malaccensis at groups I, VII, VIII, XIX; one ssp. errans at XVIII; five ssp. banksii at group IX; three ssp burmannica/burmannicoides at XI, XVIII; four ssp. siamea at VII, XI, XVIII; two ssp. microcarpa at XI, XVIII; and three ssp. zebrina at XI, XVIII), which limit inferences about the relationships among these distinct subspecies. Further, some of these AA diploids can intercross, and the classification in subspecies was merely based on spatial and temporal isolation, and some of the accessions might have an inter-subspecifc origin [2].

Despite the limited number of accessions for each subspecies, inferences from previous studies were supported. For instance, the grouping of five ssp. banksii (group IX) accessions with cultivated diploids have been reported $[2,84]$ with a clear distinction from other subspecies [84]. Musa acuminata ssp. banksii originated in Papua New Guinea and the Northern Indonesian islands, geographically isolated from the other subspecies, and it is a preferential autogamous [2]. Accession of this subspecies, presented low average heterozygosis (55.8\%) and PIC value (36.6\%). These homozygous loci for banksii and the cultivated diploids were also reported by Grapin et al. [73]. When compared with the other subspecies, banksii presented high membership values (Figure 4).

In general, there was a diversified behavior of diploids with accessions of the same subspecies in different groups and/or with different subspecies, as verified for groups XI and XVIII (Figure 4). These two groups contained a few accessions of ssp. burmannica/burmannicoides; ssp. siamea; ssp. microcarpa and ssp. zebrina, corroborating the grouping obtained based on DArT [84], and the closer relationships between ssp. errans and ssp. microcarpa [73]. However, these subspecies demonstrated distinct cytotypes based on PCR-RFLP [85]. Assembling the distinct 
subspecies into the same cluster has been reported $[2,9,84]$. This behavior could be associated with the broad variability that exists within $M$. acuminata [91] or the presence of many rare alleles in the subspecies [73] that may obscure genetic relationships. Further, differences in markers and methods of analysis, together with distinct accession names [76], and the identification of some accessions as being from a determined subspecies is still questionable [2] makes direct comparison between studies difficult.

\section{Conclusions}

The ex situ collection at 'Embrapa Mandioca Fruticultura' Center represents an important source of Musa spp. genetic resources. The accessions are characterized according to their agronomic traits, and they have been screened for disease resistance to Black- and YellowSigatoka, Fusarium wilt and Moko, and now their ploidy, genomic constitution and genetic diversity have been established. This study represents an initial effort to define genetic relationships within Musa using Bayesian statistics implemented in Structure, while exploring the codominant nature of microsatellites, not previously performed in Musa.

DNA content was believed to be a good predictor of genomic constitution in Musa, but our results confirmed that these small differences are potentially overlapped by the occurrence of homeologue recombination, discrepancies in the number of sets or portions from each parental genome, including aneuploidy. Similarly, detection of unexpected ITS rDNA alleles corroborated the hypothesis about the occurrence of recombination between the $\mathrm{A}$ and $\mathrm{B}$ genomes or between $M$. acuminata subspecies genomes. The occurrence of these phenomenons has been largely disregarded in the evolution of banana cultivars, as the "single-step domestication" hypothesis had long predominated, and these findings will have an impact in future breeding approaches.

Structure analysis enabled the efficient detection of ancestry of recently developed tetraploid hybrids by breeding programs, and for some triploid cultivars. However, for the main commercial subgroups, Structure appeared to be less efficient to detect the ancestry in diploid groups, possibly either due to diploid underrepresentation in the collection; limited number of analyzed loci evaluated; or allelic changes during evolution of the subgroups, especially the allopolyploids.

Establishing ancestry and genetic relationships by Structure allowed the identification of diploids from group IX and 'Lareina BT100' as potentially related to parentals of the sterile 'Cavendish' and 'Gros Michel' accessions, which could be used in crossing programs or chromosome manipulations (doubling) to obtain/resynthesize 'Gros Michel'/'Cavendish' hybrids. The possibility of inferring the membership of the accessions using Bayesian analysis opens possibilities for its use in marker-assisted selection by association mapping by incorporating the effects of the structure (matrix of the membership; $q$ matriz) in the population to control false positives (type I error) $[35,92]$.

With the completion of the Musa genome sequencing [93], together with the development of next-generation sequencing technology, increasing the precision of genomic information will enable an improved definition of the relationships among cultivated bananas and its diploids parental. The evaluation of a larger number of diploid accessions from the various subspecies would allow a better definition of the relationships among diploids and among triploid cultivars, therefore, to use this approach to assist and develop new strategies in breeding programs.

\section{Additional file}

Additional file 1: Table S1. Musa accessions from the ex situ collection
of 'Embrapa Mandioca Fruticultura' Center (Cruz das Almas, Brazil) with
original provenance and information on ploidy and genomic
composition derived from morphological characterization or information
from origin (passport data). Table S2. Loci used for the characterization
of the ex situ Musa collection from 'Embrapa Mandioca Fruticultura'
Center, containing a tail for fluorescent labeling, with number of
observed alleles (Na), Polymorphic Information Content (PIC), Marker
Index (MI). Underlined regions refer to tail used to label products with
fluorescence FAM, HEX, or NED. Figure S1. Mean observed heterozigosity
(Ho) and Polymorphic Information Content (PIC) for all microsatellite loci.
$\mathrm{C}$ : cultivated; W: wild. Figure S2. Histogram representing the proportion
(Y-axis) of dissimilarity (X-axis) between pairs of accessions, for all
accessions (General) and main genomic groups.

Competing interests

The authors declare that they have no competing interests.

\section{Authors' contributions}

ONJ, SOS and AF conceived the study, which was the Doctoral project of ONJ. SOS, EPA and CFF maintained and provided material from the ex situ Musa collection, and participated in the interpretation of the data. ONJ and GGS conducted the molecular analyses. JMCS conducted the flow cytometry analyses. ONJ and AF discussed the results and wrote the manuscript with the help of CFF. All authors read and approved the final manuscript.

\section{Acknowledgments}

This work was funded by FAPESP (2008/03470-0) and CNPq. Technical assistance by Luis Eduardo Fonseca was greatly appreciated. The authors (ONJ, SSO, EP, AF) are grateful for the fellowships provided by CNPq and GGS to FAPESP (2010/01398-0)

\section{Author details}

${ }^{1}$ Centro de Energia Nuclear na Agricultura, Universidade de São Paulo, Av. Centenário, 303, CP 96, Piracicaba, SP 13400-970, Brazil. Escola Superior de Agricultura "Luiz de Queiroz", Universidade de São Paulo, Av. Pádua Dias, 11, Piracicaba, SP 13418-900, Brazil. 'EMBRAPA Mandioca Fruticultura, R. Embrapa s/n, Cruz das Almas, BA 44380-000, Brazil. ${ }^{4}$ Instituto de Ciências Biológicas, Universidade Federal de Juiz de Fora, Campus Martelos, Juiz de Fora, MG 36016-900, Brazil.

Received: 4 July 2012 Accepted: 22 February 2013

Published: 12 March 2013 


\section{References}

1. Simmonds NW: The evolution of the bananas. London: Longmans Green; 1962.

2. Carreel F, Leon DG, Lagoda P, Lanaud C, Jenny C, Horry JP, Montcel TH: Ascertaining maternal and paternal lineage within Musa by chloroplast and mitochondrial DNA RFLP analyses. Genome 2002, 45(4):679-692.

3. De Langhe E, Vrydaghs L, Maret P, Perrier X, Denham T: Why Bananas Matter: An introduction to the history of banana domestication. Ethnobot Res Appl 2009, 7(1):165-177.

4. Valmayor RV: Classification and characterization of Musa exotica, $M$. alinsanaya and M. acuminata ssp. errans. Infomusa 2001, 10(2):35-39.

5. Boonruangrod R, Fluch S, Burg K: Elucidation of origin of the present day hybrid banana cultivars using the $5^{\prime}$ ETS rDNA sequence information. Mol Breed 2009, 24(1):24-77.

6. Simmonds NW, Shepherd K: The taxonomy and origin of the cultivated bananas. Botany J Linnean Soc London 1955, 55(359):302-312.

7. Carreel F, Faure S, Gonzalez De Leon D, Lagoda PJL, Perrier X, Bakry F, Tezenas Du Montcel H, Lanaud C, Horry JP: Evaluation de la diversité genetique chez les bananiers diploides (Musa spp.). Genet Sel Evol 1994, 26(1):125-136

8. Raboin LM, Carreel F, Noyer JL, Baurens FC, Horry JP, Bakry F, Du Montcel HT, Ganry J, Lanaud C, Lagoda PJL: Diploid ancestors of triploid export banana cultivars: molecular identification of $2 n$ restitution gamete donors and $n$ gamete donors. Mol Breed 2005, 16(4):333-341.

9. Perrier X, Bakry F, Carreel F, Jenny C, Horry JP, Lebot V, Hippolyte I: Combining biological approaches to shed light on evolution of edible bananas. Ethnobot Res Appl 2009, 7(1):199-216.

10. Perrier X, Langhe E, Donohue M, Lentfer C, Vrydaghs L, Bakry F, Carreel F, Hippolyte I, Horry J-P, Jenny C, Lebot V, Risterucci A-M, Tomekpe K, Doutrelepont H, Ball T, Manwaring J, Maret P, Denham T: Multidisciplinary perspectives on banana (Musa spp.) domestication. PNAS 2011, 5:1-8.

11. INIBAP.Genetic improvement: the only sustainable solution- A tribute to our colleagues. In INIBAP annual report 2001. Montpellier; 2002:34-37. http://www.musalit.org/pdf/IN030400_en.pdf.

12. Robinson JC: Bananas and Plantains. UK: CAB International; 1996

13. Wang XL, Chiang TY, Roux N, Hao G, Ge XJ: Genetic diversity of wild banana (Musa balbisiana Colla) in China as revealed by AFLP markers. Genet Resour Crop Evol 2007, 54(5):1125-1132.

14. Oselebe HO, Tenkouano A: Ploidy versus gender effects on inheritance of quantitative traits in Musa species. Aust J Crop Sci 2009, 3(6):367-373.

15. Shepherd K: Cytogenetics of the genus Musa. Montpellier: INIBAP; 1999.

16. Tenkouano A, Ortiz R, Vuylsteke D: Combining ability for yield and plant phenology in plantain-derived populations. Euphytica 1998, 104(3):151-158

17. Doležel J, Lysak MA, Van den Houwe I, Doleželova HM, Roux N: Use of flow cytometry for rapid ploidy determination in Musa species. Infomusa 1997, 6(1):6-9.

18. Doležel J, Lysak MA, Doleželova M, Valarik M: Analysis of Musa genome using flow cytometry and molecular cytogenetics. Infomusa 1999, 8(1):3-4.

19. Pillay M, Ogundiwiny E, Tenkouanod A, Doležel J: Ploidy and genome composition of Musa germplasm at the International Institute of Tropical Agriculture (IITA). Afr J Biotechnol 2006, 5(13):1224-1232.

20. Nwakanma DC, Pillay M, Okoli BE: PCR-RFLP of the ribosomal DNA internal transcribed spacers (ITS) provides markers for the $A$ and $B$ genomes in Musa L. Theor App/ Genet 2003, 108:154-159.

21. Ning SP, Xu LB, Lu Y, Huang BZ, Ge XJ: Genome composition and genetic diversity of Musa germplasm from China revealed by PCR-RFLP and SSR markers. Sci Hortic 2007, 114(4):281-288.

22. Creste S, Tulmann Neto A, Silva SO, Figueira A: Genetic characterization of banana cultivars (Musa spp.) from Brazil using microsatellite markers. Euphytica 2003, 132(3):259-268.

23. Creste $S$, Benatti TR, Orsi MR, Risterucci AM, Figueira A: Isolation and characterization of microsatellite loci from a commercial cultivar of Musa acuminate. Mol Ecol Notes 2006, 6(2):303-306.

24. Crouch $\mathrm{JH}$, Crouch HK, Tenkouano A, Ortiz R: VNTR-based diversity analysis of 2x and 4x full-sib Musa hybrids. Electron J Biotechnol 1999, 2(3):130-1139.

25. Ude G, Pillay M, Nwakanma D, Tenkouano A: Genetic diversity in Musa acuminata Colla and Musa balbisiana Colla and some of their natural hybrids using AFLP markers. Theor Appl Genet 2002, 104(8):1246-1252.

26. Creste S, Tulmann Neto A, Vencovsky R, Silva SO, Fiqueira A: Genetic diversity of Musa diploid and triploid accessions from the Brazilian banana breeding program estimated by microsatellite markers. Genet Resour Crop Evol 2004, 51(7):723-733.
27. Jesus ON, Câmara TR, Ferreira CF, Silva SO, Pestana KN, Soares TL: Diferenciação molecular de cultivares elites de bananeira. Pesqui Agropecu Bras 2006, 41(12):1739-1748

28. Amorim EP, Reis RV, Santos-Serejo JA, Amorim VBO, Silva SO: Variabilidade genética estimada entre diplóides de banana por meio de marcadores microssatélites. Pesqui Agropecu Bras 2008, 43(8):1045-1052.

29. Christelová P, Valárik M, Hřibová E, den Houwel V, Channelière S, Roux N, Doležel J: A platform for efficient genotyping in Musa using microsatellite markers. AoB Plants 2011, 1:1-14.

30. Pritchard JK, Stephens M, Rosenberg NA, Donnelly P: Association mapping in structured populations. Am J Hum Genet 2000, 67(1):170-181.

31. Pritchard JK, Stephens M, Donnelly P: Inference of population structure using multilocus genotype data. Genetics 2000, 155:945-959.

32. Pritchard JK, Wen W: Documentation for structure software, Version 2.3. Chicago: The University of Chicago: Department of Human Genetics; 2011. http://pritch.bsd.uchicago.edu/structure.html.

33. Stajner N, Satovic Z, Cerenak A, Javornik B: Genetic structure and differentiation in hop (Humulus lupulus L.) as inferred from microsatellites. Euphytica 2008, 161:301-311.

34. Odong TL, Heerwaarden J, Jansen J, Hintum TJL, Eeuwijk FA: Determination of genetic structure of germplasm collections: are traditional hierarchical clustering methods appropriate for molecular marker data? Theor Appl Genet 2011, 123:195-205.

35. Yu J, Pressoir G, Briggs WH, Bi IV, Yamasaki M, Doebley JF, McMullen MD, Gaut BS, Nielsen DM, Holland JB, Kresovich S, Buckler ES: A unified mixedmodel method for association mapping that accounts for multiple levels of relatedness. Nat Genet 2005, 38:203-208.

36. Kraakman ATW, Martinez F, Mussiraliev B, Van Eeuwijk FA, Niks RE: Linkage disequilibrium mapping of morphological, resistance, and other agronomically relevant traits in modern spring barley cultivars. Mol Breed 2006, 17:41-58.

37. Kraakman ATW, Niks RE, Van Den Berg PMMM, Stam P, Van Eeuwijk FA: Linkage Disequilibrium mapping of yield and yield stability in modern spring barley cultivars. Genetic 2004, 68:435-446.

38. Malosetti M, Van der Linden CG, Vosman B, Van Eeuwijk FA: A mixedmodel approach to association mapping using pedigree information with an illustration of resistance to Phytophthora infestans in potato. Genetics 2007, 175:879-889.

39. Silva SO, Matos AP, Alves EJ: Melhoramento genético de bananeira. Pesquisa Agropecuária Brasileira 1998, 33(5):693-703.

40. Fauré SJL Noyer J-PHorry F, Bakry C, Gonzàlez-de-León D, Lanaud: A molecular marker based linkage map of diploid bananas (Musa acuminata). Theor Appl Genet 1993, 87:517-526.

41. Heslop-Harrison JS, Schwarzacher T: Domestication, genomics and the future for banana. Ann Bot 2007, 100(5):1073-1084.

42. MGIS-Germplasm Information System. http://www.crop-diversity.org/banana/.

43. Doležel J, Greilhuber J, Suda J: Estimation of nuclear DNA content in plants using flow cytometry. Nat Protoc 2007, 2:2233-2244.

44. Doležel J: Application of flow cytometry for the study of plant genomes. J Appl Genet 1997, 38(3):285-302.

45. White TJ, Bruns T, Lee S, Taylor J: Amplification and direct sequencing of fungal ribosomal RNA genes for phylogenies. In PCR protocols: a guide to methods and applications. Volume1. 1st edition. Edited by Innis MA, Gelfand DH, Sninsky JJ, White TJ. New York: Academic Press; 1990:315-322

46. Jarret RL, Bhat KV, Cregan P, Ortiz R, Vuylsteke D: Isolation of microsatellite DNA markers in Musa. Infomusa 1994, 3(1):3-4.

47. Lagoda PJL, Noyer JL, Dambier D, Baurens FC, Grapin A, Lanaud C: Sequence tagged microsatellite site (STMS) markers in the Musaceae. Mol Ecol 1998, 7(5):657-666.

48. Buhariwalla HK, Jarret RL, Jayashree B, Crouch JH, Ortiz R: Isolation and characterization of microsatellite markers from Musa balbisiana. Mol Ecol Notes 2005, 5(2):327-330.

49. Missiaggia A, Grattapaglia D: Plant microsatellite genotyping with 4-color fluorescent detection using multiple-tailed primers. Genet Mol Res 2006, 1(5):72-78.

50. Roldan-Ruiz I, Dendauw JE, Van Bockstaele E, Depicker A, Loose M: AFLP markers reveal high polymorphic rates in ryegrasses (Lolium spp.). Mol Breed 2000, 6:125-126. 
51. Varshney RK, Chabane K, Hendre PS, Aggarwal RK, Graner A: Comparative assessment of EST-SSR, EST-SNP and AFLP markers for evaluation of genetic diversity and conservation of genetic resources using wild, cultivated and elite barleys. Plant Sci 2007, 173:638-649.

52. Liu K, Muse SV: Powermarker: Integrated analysis environment for genetic marker data. Bioinformatics 2005, 21(9):2128-2129.

53. Cruz CD: Programas GENES-versão Windows 2005.6.1. Viçosa: UFV; 2001.

54. Saitou N, Nei M: The Neighbor-joining method: A new method for reconstructing phylogenetic trees. Mol Biol Evol 1987, 4(4):406-425.

55. Tamura K, Dudley J, Nei M, Kumar S, MEGA4: Molecular Evolutionary Genetics Analysis (MEGA) software version 4.0. Mol Biol Evol 2007, 24:1596-1599.

56. Falush D, Stephens M, Pritchard JK: Inference of population structure using multilocus genotype data: linked loci and correlated allele frequencies. Genetics 2003, 164(4):1567-1587.

57. Jing R, Vershinin A, Grzebyta J, Shaw P, Smýkal P, Marshall D, Ambrose MJ Noel Ellis TH, Flavell AJ: The genetic diversity and evolution of field pea (Pisum) studied by high throughput retrotransposon based insertion polymorphism (RBIP) marker analysis. BMC Evol Biol 2010, 10:44.

58. Evanno G, Regnaut S, Goudet J: Detecting the number of clusters of individuals using the software structure: a simulation study. $\mathrm{Mol}$ Ecol 2005, 14(8):2611-2620.

59. Santos-Serejo JA, Souza EH, Souza FVD, Soares TL, Silva SO: Caracterização morfológica de bananeiras ornamentais. Magistra 2007, 19(4):326-332

60. Baraket G, Chatti K, Saddoud O, Abdelkarim AB, Mars M, Trifi M, Hannachi AS: Comparative assessment of SSR and AFLP Markers for Evaluation of Genetic Diversity and Conservation of Fig, Ficus carica L., genetic resources in Tunisia. Plant Mol Biol Rep 2011, 29:171-184.

61. Doležel J, Valárik M, Vrána J, Lysák MA, Hibová E, Bartos J, Gasmanová N, Doleželová M, Safár J, Simková H: Molecular cytogenetics and cytometry of bananas (Musa spp.). In Banana Improvement: cellular molecular biology and induced mutations, Volume 1. Edited by Jain SM, Swennen R. Leuven: Science Publishers; 2001:229-244.

62. Nsabimana A, Staden J: Ploidy investigation of bananas (Musa spp.) from the Nationalbanana Germplasm Collection at Rubona-Rwanda by flow cytometry. S Afr J Clin Sci Bot 2006, 72(2):302-305.

63. Lysák MA, Doleželová M, Horry JP, Swennen R, Doležel J: Flow cytometric analysis of nuclear DNA content in Musa. Theor Appl Genet 1999, 98(8):1344-1350.

64. Doležel J, Doleželová M, Novák FJ: Flow cytometric estimation of nuclear DNA amount in diploid bananas (Musa acuminata and M. balbisiana). Biol Plant 1994, 3:351-357.

65. D'Hont A, Paget-Goya A, Escoute J, Carreel F: The interspecific genome structure of cultivated banana, Musa spp. revealed by genomic DNA in situ hybridization. Theor Appl Genet 2000, 100(2):177-183.

66. De Langhe E, Hřibová E, Carpentier S, Doležel J, Swennen R: Did backcrossing contribute to the origin of hybrid edible bananas? Ann Bot 2010, 106:849-857.

67. Jeridi M, Bakry F, Escoute J, Fondi E, Carreel F, Ferchichi A, D'Hont A, Rodier-Goud M: Homoeologous chromosome pairing between the $\mathrm{A}$ and $B$ genomes of Musa spp. revealed by genomic in situ hybridization. Ann Bot 2011, 108:975-981.

68. Pillay M, Nwakanma DC, Tenkouano A: Identification de RAPD markers linked to A and B genome sequences in Musa L. Genome 2000, 43(5):763-767.

69. Crouch HK, Crouch JH, Jarret RL, Cregan PB, Ortiz R: Segregation at microssatellite loci in haploid and diploid gametes of Musa. Crop Sci 1998, 38(1):211-217.

70. Retnoningsih R, Megia R, Hartana A: Microsatellite markers for classifying and analysing genetic relationship between banana cultivars in Indonesia. Acta Horticulturae 2011, 897:53-160.

71. Hřibová E, Cizkova J, Christelova P, Taudien S, de Langhe E, Doležel J: The ITS1-5.8S-ITS2 sequence region in the Musaceae: structure, diversity and use in molecular phylogeny. PlosOne 2011, 6(3):e17863.

72. Swangpol S, Volkaert H, Sotto RC, Seelanant: Utility of selected non-coding chloroplast DNA sequences for lineage assessment of Musa interspecific hybrids. J Biochem Mol Biol 2007, 40(4):577-587.

73. Grapin A, Noyer JL, Carreel F, Dambier D, Baurens FC, Lanaud C, Lagoda PJL: Diploid Musa acuminata genetic diversity assayed with sequence-tagged microsatellite sites. Electrophoresis 1998, 19(8-9):1374-1380.

74. Dessauw D: Étude des facteurs de la sterilité du bananier (Musa spp.) et des relations cytotaxononomiques entre $M$. acuminanta et $M$. balbisiana Colla. Fruits 1988, 43:539-700.
75. Ortiz R: Occurrence and Inheritance of 2n Pollen in Musa. Ann Bot 1997, 79:449-453.

76. Hippolyte I, Jenny C, Gardes L, Bakry F, Rivallan R, Pomies V, Cubry P, Tomekpe K, Risterucci AM, Roux N, Rouard M, Arnaud E, Kolesnikova-Allen M, Perrier X: Foundation characteristics of edible Musa triploids revealed from allelic distribution of SSR markers. Annals of Botany 2012, 109:937-951.

77. Oriero CE, Odunola OA, LoCo Y, Ingelbrecht I: Analysis of B-genome derived simple sequence repeat (SSR) markers in Musa spp. Afr J Biotechnol 2006, 5(2):126-128.

78. Noyer JL, Causse S, Tomekpe K, Bouet A, Baurens FC: A new image of plantain diversity assessed by SSR, AFLP and MSAP markers. Genetica 2005, 124(1):61-69.

79. Crouch HK, Crouch JH, Madsen S, Vuylsteke DR, Ortiz R: Comparative analysis of phenotypic and genotypic diversity among plantain landraces (Musa spp. AAB group). Theor App/ Genet 2000, 101(7):1056-1065.

80. Ortiz R: Morphological variation in Musa germplasm. Genet Resour Crop Evol 1997, 44(5):393-404

81. Sharbel TF, Haubold B, Mitchell-Olds T: Genetic isolation by distance in Arabidopsis thaliana: biogeography and postglacial colonization of Europe. Mol Ecol 2000, 9:2109-2118.

82. Flint-Garcia SA, Thornsberry JM, Buckler ES: Structure of linkage disequilibrium in plants. Annu Rev Plant Physiol 2003, 54:357-374

83. Cruz FS, Gueco LS, Damasco OP, Huelgas VC, Banasihan IG, Lladones RV, Van Den Bergh I: Molina AB:Catalogue of introduced and local banana cultivars in the Philippines: results of a demonstration trial by the Institute of plant breeding. Laguna: University of the Philippines Los Baños, IPB-UPLB, Bioversity International and DA-BAR; 2007.

84. Risterucci AM, Hippolyte I, Perrier X, Xia L, Caig V, Evers M, Huttner E, Kilian A, Glaszmann JC: Development and assessment of Diversity Arrays Technology for high-throughput DNA analyses in Musa. Theor Appl Genet 2009, 119(6):1093-1103.

85. Boonruangrod R, Desai D, Fluch S, Berenyi M, Burg K: Identification of cytoplasmic ancestor gene-pools of Musa acuminata Colla and Musa balbisiana Colla and their hybrids by chloroplast and mitochondrial haplotyping. Theor App/ Genet 2008, 118(1):43-55.

86. Gernand D, Rutten T, Pickering R, Houben A: Elimination of chromosomes in Hordeum vulgare $\mathrm{x}$. bulbosum crosses at mitosis and interphase involves micronucleus formation and progressive heterochromatinization. Cytogenet Genome Res 2006, 114(2):69-74.

87. Sanei M, Pickering R, Kumke K, Nasuda S, Houben A: Loss of centromeric histone $\mathrm{H} 3$ (CENH3) from centromeres precedes uniparental chromosome elimination in interspecific barley hybrids. PNAS 2011, 108(33):13373-13374.

88. Jeridi M, Perrier X, Rodier-Goud M, Ferchichi A, D'Hont A, Bakry F: Cytogenetic evidence of mixed disomic and polysomic inheritance in an allotetraploid (AABB) Musa genotype. Ann Bot 2012, 110(8):1593-1606.

89. Renny-Byfield S, Chester M, Kovarik A, Le Comber SC, Grandbastien M-A, Deloger M, Nichols RA, Macas J, Novák P, Chase MW, Leitch AR: Next generation sequencing reveals genome downsizing in allotetraploid Nicotiana tabacum, predominantly through the elimination of paternally derived repetitive DNAs. Mol Biol Evol 2011, 28:2843-2854

90. Hribová E, Dolezelová M, Town CD, Macas J, Doležel J: Isolation and characterization of the highly repeated fraction of the banana genome. Cytogenet Genome Res 2007, 119(3-4):268-74.

91. Jarret RL, Gawel N, Whittemore A, Sharrock S: RFLP-based phylogeny of Musa species in Papua New Guinea. Theor Appl Genet 1992, 84(5-6):579-584.

92. Simko I: Population structure in cultivated lettuce and its impact on association mapping. J Am Soc Hortic Sci 2008, 133(1):61-68.

93. D'Hont A, et al: The banana (Musa acuminata) genome and the evolution of monocotyledonous plants. Nature 2012, 488:213-217.

doi:10.1186/1471-2229-13-41

Cite this article as: de Jesus et al:: Genetic diversity and population structure of Musa accessions in ex situ conservation. BMC Plant Biology 2013 13:41. 